RAUL MARTINS JUNIOR

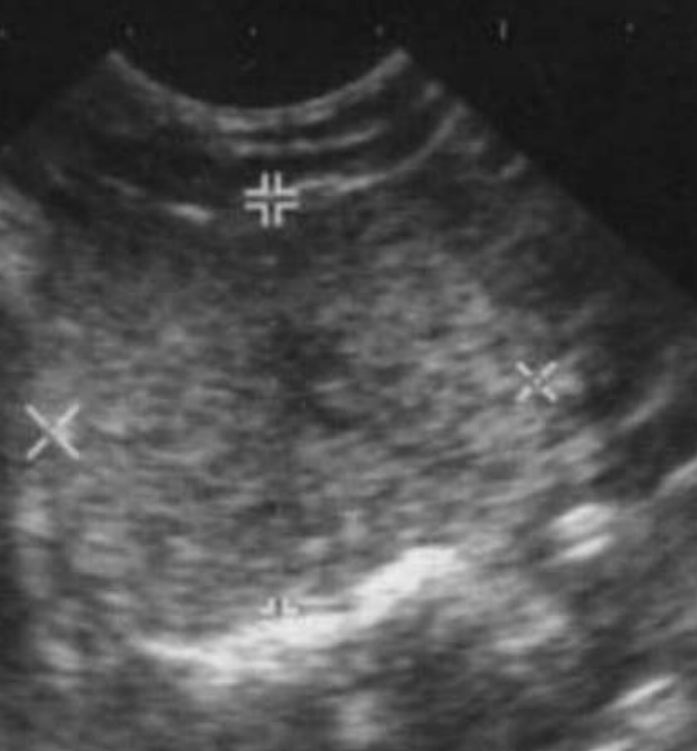

PADRONIZAÇÃO DAS MEDIDAS DA PRÓSTATA DE CÃES DE DIFERENTES PESOS E IDADES PELO $\Rightarrow$ XAME ULTRA-SONOGRÁFICO 
RAUL MARTINS JUNIOR

\title{
Padronização das medidas da próstata de cães de diferentes pesos e idades pelo exame ultra-sonográfico
}

\begin{abstract}
Dissertação apresentada ao Programa de Pós-Graduação em Clínica Cirúrgica Veterinária da Faculdade de Medicina Veterinária e Zootecnia da Universidade de São Paulo para obtenção do título de Mestre em Medicina Veterinária
\end{abstract}

\section{Departamento}

Cirurgia

\section{Área de Concentração \\ Clínica Cirúrgica Veterinária}

\section{Orientador}

Prof. Dr. Franklin de Almeida Sterman 
Autorizo a reprodução parcial ou total desta obra, para fins acadêmicos, desde que citada a fonte.

DADOS INTERNACIONAIS DE CATALOGAÇÃO-NA-PUBLICAÇÃO

(Biblioteca Virginie Buff D’Ápice da Faculdade de Medicina Veterinária e Zootecnia da Universidade de São Paulo)

T.1805 $\begin{aligned} & \text { Martins Junior, Raul } \\ & \text { PMVZ }\end{aligned}$
Padronização das medidas da próstata de cães de diferentes pesos e
Martins Junior, 2006.
85 f. : il.
Dissertação (mestrado) - Universidade de São Paulo. Faculdade de
Medicina Veterinária e Zootecnia. Departamento de Cirurgia, 2006.

Programa de Pós-Graduação: Clínica Cirúrgica Veterinária.

Área de concentração: Clínica Cirúrgica Veterinária.

Orientador: Prof. Dr. Franklin de Almeida Sterman.

1. Cães. 2. Próstata (Veterinária). 3. Ultrasonografia. I. Título. 


\title{
UNIVERSIDADE DE SÃO PAULO \\ Faculdade de Medicina Veterinária e Zootecnia
}

\author{
Comissão Bioética
}

\section{CERTIFICADO}

Certificamos que o Projeto intitulado "Padronização das medidas da próstata de cães de diferentes raças e tamanhos pelo exame ultrasonográfico", protocolo n808/2005, utilizando 60 (sessenta) cães, sob a responsabilidade do Prof. Dr. Franklin de Almeida Sterman, está de acordo com os princípios éticos de experimentação animal da Comissão de Bioética da Faculdade de Medicina Veterinária e Zootecnia da Universidade de São Paulo e foi aprovado "ad referendun".

(We certify that the Research "Canine prostate measurement standardization in different breeds and sizes by the ultrasound examination", protocol number 808/2005, under the responsibility of Prof. Dr. Franklin de Almeida Sterman, utilizing 60 (sixty) dogs, agree with Ethical Principles in Animal Research adopted by Bioethic Commission of the Faculty of Veterinary Medicine and Zootechny of University of São Paulo and was approved "ad referendun", meeting).

São Paulo, 25 de novembro de 2005

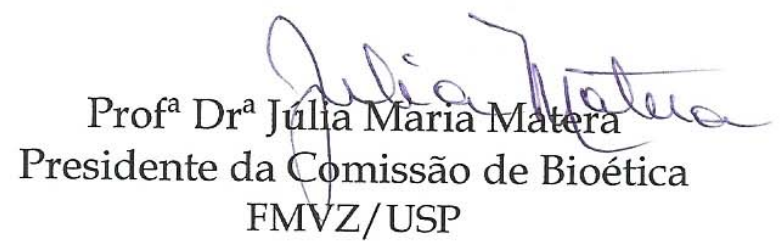

Av. Prof. Dr. Orlando Marques de Paiva, no 87 - 05508-270 - Cidade Universitária "Armando de Salles Oliveira". Fax: (11) 3032-2224 - fones: (11) 309107676/7671 - email: fmvz@edu.usp.br 


\section{FOLHA DE AVALIAÇÃO}

Nome : MARTINS JUNIOR, Raul

Título: Padronização das medidas da próstata de cães de diferentes pesos e idades pelo exame ultra-sonográfico

Dissertação apresentada ao Programa de Pós-Graduação em Clínica Cirúrgica Veterinária da Faculdade de Medicina Veterinária e Zootecnia da Universidade de São Paulo para obtenção do título de Mestre em Medicina Veterinária

Data:

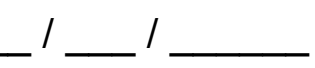

Banca examinadora

Prof. Dr. Instituição:

Assinatura: Julgamento:

Prof. Dr. Instituição:

Assinatura: Julgamento:

Prof. Dr. Instituição:

Assinatura: Julgamento: 
"Se puder salvar um coração em tormento,

Não terei vivido em vão;

Se puder aliviar de uma vida o sofrimento,

Ou aplacar a dor de uma paixão,

Ou ajudar quase extinto passarinho a subir ao

ninho e ao vento,

Não terei vivido em vão."

Emily Dickinson 
Dedico este trabalho aos meus pais, Raul e Lina e à minha irmã Cíntia. Amo muito vocês! 


\section{AGRADECIMENTOS}

Ao Professor Franklin de Almeida Stermann por ter confiado em meu trabalho e ter me dado à oportunidade de realizar esta conquista.

À Luciane Kanayama pelos seus ensinamentos, pelo seu auxílio na realização do experimento prático e pela sua amizade.

À Silvana Unruh que sempre me ajudou e me apoiou com atenção e carinho.

À Professora Márcia Mery pelo estímulo, apoio e interesse sempre constantes.

Ao Professor Alexandre Lima Andrade por estar sempre ao meu lado, me transmitindo todo seu conhecimento de forma solidária.

À Caterina Muramoto pela simplicidade de suas atitudes e pelo carinho que sempre teve em ajudar.

À Viviane Jorge por acreditar em minha capacidade e permitir que eu continue o meu aprendizado.

À Tilde Froes por esclarecer as dúvidas e pelos conselhos sempre gentis.

À Georgea Bignardi Jarretta por estar sempre prestes a atender meus pedidos de apoio e colaboração.

Aos Professores do Departamento de Cirurgia da Faculdade de Medicina Veterinária e Zootecnia da Universidade de São Paulo pelo carinho e atenção que sempre recebi.

À Inês Esteves pela orientação na realização da análise estatística. 
A todos os funcionários do HOVET-USP que sempre estiveram dispostos a ajudar.

Ao secretário da pós-graduação, Belarmino Ney Pereira por estar sempre prestes a resolver os problemas da melhor forma possível.

Aos funcionários da biblioteca da FMVZ/USP, em especial à Elza e à Fátima pelas imprescindíveis colaborações na execução deste trabalho. 


\section{RESUMO}

MARTINS JUNIOR, R. Padronização das medidas da próstata de cães de diferentes pesos e idades pelo exame ultra-sonográfico. [Ultrasonographic standardization of prostatic measurements in dogs with different ages and weights]. 2006. 85 f. Dissertação (Mestrado em Medicina Veterinária) Faculdade de Medicina Veterinária e Zootecnia, Universidade de São Paulo, São Paulo, 2006.

O objetivo deste estudo foi o de medir in vivo as dimensões da próstata, pelo exame ultra-sonográfico, de cães de diferentes tamanhos, com idade entre 1 e 5 anos. Foram realizados exames em 47 cães, sem processos patológicos aparentes. Os pacientes foram divididos em dois grupos de acordo com a idade, Grupo 1: cães entre 12 e 30 meses e Grupo 2: cães entre 31 e 60 meses. Cada grupo foi subdividido em três subgrupos de acordo com o peso. Subgrupos 1 e 4 com animais até $10 \mathrm{~kg}$, Subgrupos 2 e 5 com animais entre 11 e $25 \mathrm{~kg}$ e Subgrupos 3 e 6 com animais acima de $25 \mathrm{~kg}$ sendo que os Subgrupos 1 a 3 pertencem ao Grupo 1 e os Subgrupos 4 a 6 pertencem ao Grupo 2. As imagens em corte longitudinal e transversal permitiram a observação da próstata, localizada caudalmente à bexiga urinária, de formato arredondado, de contornos regulares e definidos e de ecogenicidade maior que a do baço. Comprimento e altura foram mensurados no plano longitudinal, já a largura foi medida no plano transversal. O Subgrupo 1 apresentou medidas prostáticas de comprimento: $1,19( \pm 0,16 \mathrm{~cm})$; de altura: $1,17( \pm 0,2 \mathrm{~cm})$ e de largura: 1,41 $( \pm 0,24 \mathrm{~cm})$, valores menores que os obtidos no Subgrupo 4 que apresentou comprimento: $2,14( \pm 0,13 \mathrm{~cm})$; altura: $2,12( \pm 0,16 \mathrm{~cm})$ e largura de 2,59 $( \pm 0,21 \mathrm{~cm})$. O Subgrupo 2 apresentou valores prostáticos de comprimento: $2,17( \pm 0,11 \mathrm{~cm})$; de altura: $2,04( \pm 0,15 \mathrm{~cm})$ e de largura: $2,64( \pm 0,13 \mathrm{~cm})$, valores 
menores que os obtidos no Subgrupo 5 que apresentou comprimento: 2,81 $( \pm 0,44 \mathrm{~cm})$; altura $3,73:( \pm 0,37 \mathrm{~cm})$ e largura de $3,29( \pm 0,38 \mathrm{~cm})$. O Subgrupo 3 apresentou valores prostáticos de comprimento $3,09( \pm 0,21 \mathrm{~cm})$; de altura: 2,93 $( \pm 0,21 \mathrm{~cm})$ e de largura: $3,63( \pm 0,19 \mathrm{~cm})$, valores menores que os obtidos no Subgrupo 6 que apresentou comprimento: $3,47( \pm 0,31 \mathrm{~cm})$; altura: 3,35 $( \pm 0,35 \mathrm{~cm})$ e largura de $4,03( \pm 0,28 \mathrm{~cm})$. A correlação foi forte entre os valores prostáticos determinados e a massa corpórea dos cães estudados.

Palavras-chave: Cães. Próstata (Veterinária). Ultrasonografia. 


\begin{abstract}
MARTINS JUNIOR, R. Ultrasonographic standardization of prostatic measurements in dogs with different ages and weights. [Padronização das medidas da próstata de cães de diferentes pesos e idades pelo exame ultrasonográfico]. 2006. 85f. Dissertação (Mestrado em Medicina Veterinária) Faculdade de Medicina Veterinária e Zootecnia, Universidade de São Paulo, São Paulo, 2006.
\end{abstract}

The aim of this study was ultrasonographically assess the prostatic dimensions in dogs of different sizes, aging from 1 to 5 years-old. Forty-seven examinations were done, in dogs with no clinical diseases. The patients were divided into two groups according to their ages, such as: Group 1 - from 12 to 30 months-old and Group 2 - from 31 to 60 months-old. Each group was divided into 3 other groups according to their weight. Subgroup 1 and 4: up to $10 \mathrm{Kg}$, subgroup 2 and 5: from 11 to $25 \mathrm{Kg}$ and subgroups 3 and 6: over $25 \mathrm{Kg}$ (subgroups 1 to 3 were inserted in Group 1 and subgroups 4 to 6 were inserted in Group 2). The sagittal and transverse planes on ultrasonographic examination provided the entire visualization of the prostate, which was round to normal-shaped, lies caudally to the urinary bladder, with smooth margins and hyperechoic to the spleen. Their length and height were measured on sagittal plane and the width was measured on transverse plane. Regarding the subgroup 1, the mean prostatic length was $1,19 \mathrm{~cm}( \pm 0,16 \mathrm{~cm})$, the mean prostatic height was 1,17 $\mathrm{cm}( \pm 0,2 \mathrm{~cm})$ and the mean prostatic width was $1,41 \mathrm{~cm}( \pm 0,24 \mathrm{~cm})$, and these measurements showed to be shorter than the ones from subgroup 4, such as $2,14 \mathrm{~cm}( \pm 0,13)$ as for the mean length, $2,12 \mathrm{~cm}( \pm 0,16 \mathrm{~cm})$ as for the mean height and finally $2,59 \mathrm{~cm}( \pm 0,21 \mathrm{~cm})$ as for the mean width. Regarding the subgroup 2, the mean prostatic length was $2,17 \mathrm{~cm}( \pm 0,11)$, the mean height 
was $2,04( \pm 0,15 \mathrm{~cm})$ and the mean width was $2,64 \mathrm{~cm}( \pm 0,13)$, and these measurements showed to be shorter than the ones from subgroup 5 , such as $2,81 \mathrm{~cm}( \pm 0,44)$ as for mean length, $3,73 \mathrm{~cm}( \pm 0,37 \mathrm{~cm})$ as for the mean height and finally $3,29 \mathrm{~cm}( \pm 0,38 \mathrm{~cm})$ as for the mean width. Regarding the subgroup 3 , the mean prostatic length was $3,09 \mathrm{~cm}( \pm 0,21)$, the mean height was $2,93( \pm 0,21 \mathrm{~cm})$ and the mean width was $3,63 \mathrm{~cm}( \pm 0,19)$, and these measurements showed to be shorter than the ones from subgroup 6 , such as $3,47 \mathrm{~cm}( \pm 0,31)$ as for mean length, $3,35 \mathrm{~cm}( \pm 0,35 \mathrm{~cm})$ as for the mean height and finally $4,03 \mathrm{~cm}( \pm 0,28 \mathrm{~cm})$ as for the mean width. There was a high correlation between the prostatic dimensions and the body mass of theses dogs.

Key words: Dogs. Ultrasonography (Veterinary). Prostate. 


\section{LISTA DE FIGURAS}

Figura 1 - Aparelho de ultra-sonografia TOKIMEC CS-3030, utilizado para avaliação ultra-sonográfica dos pacientes, e mensuração das próstatas - FMVZ/USP - São Paulo, Novembro de 2006

Figura 2 - Impressora Sony, modelo UP-895MD - FMVZ/USP - São Paulo, Novembro de 2006

Figura 3 - Localização de acesso ultra-sonográfico transabdominal à próstata do cão - FMVZ/USP - São Paulo, Novembro de 2006.

Figura 4 - Transdutores linear de $7,5 \mathrm{MHz}$ (esquerda) e convexo de $5,0 \mathrm{MHz}$ (direita) utilizados para avaliação ultra-sonográfica da próstata canina - FMVZ/USP - São Paulo, Novembro de 2006.

Figura 5 - Plano transversal de varredura na avaliação ultra-sonográfica da próstata canina - FMVZ/USP - São Paulo, Novembro de 2006

Figura 6 - Imagem ultra-sonográfica de próstata normal em cão, corte transversal - FMVZ/USP - São Paulo, Novembro de 2006.

Figura 7 - Desenho esquemático da medida latero-lateral da próstata canina no exame ultra-sonográfico, corte transversal - FMVZ/USP - São Paulo, Novembro de 2006.

Figura 8 - $\quad$ Plano longitudinal de varredura na avaliação ultra-sonográfica da próstata canina - FMVZ/USP - São Paulo, Novembro de 2006

Figura 9 - Imagem ultra-sonográfica de próstata normal em cão, corte longitudinal - FMVZ/USP - São Paulo, Novembro de 2006 .

Figura 10 - Desenho esquemático das medidas crânio-caudal (a) e dorsoventral (b) da próstata canina no exame ultra-sonográfico, corte longitudinal - FMVZ/USP - São Paulo, Novembro de 2006. 
Figura 11 - Imagem ultra-sonográfica da próstata canina normal, em corte transversal identificando as medidas de: largura, latero $(X)$ - lateral (X) e altura, dorso (+) - ventral (+) - FMVZ/USP - São Paulo, Novembro de 2006.................................................................... 52

Figura 12 - Imagem ultra-sonográfica da próstata canina normal, em corte longitudinal identificando as medidas de: comprimento, crânio (X) caudal (X) e altura, dorso (+) - ventral (+) - FMVZ/USP - São Paulo, Novembro de 2006. 


\section{LISTA DE TABELAS}

Tabela 1 - Medidas da próstata de cães do Grupo 1 (animais com idade até 30 meses), Subgrupo 1 (peso até $10 \mathrm{~kg}$ ), atendidos no Serviço de Diagnóstico por Imagem do HOVET-USP, São Paulo, Novembro de 2006

Tabela 2 - Medidas da próstata de cães do Grupo 1 (animais com idade até 30 meses), Subgrupo 2 (peso entre 11 e $25 \mathrm{~kg}$ ), atendidos no Serviço de Diagnóstico por Imagem do HOVET - USP, São Paulo, Novembro de 2006

Tabela 3 - Medidas da próstata de cães do Grupo 1 (animais com idade até 30 meses), Subgrupo 3 (peso acima de $25 \mathrm{~kg}$ ), atendidos no Serviço de Diagnóstico por Imagem do HOVET - USP, São Paulo, Novembro de 2006

Tabela 4 - Medidas da próstata de cães do Grupo 2 (animais com idade entre 31 e 60 meses), Subgrupo 4 (peso até $10 \mathrm{~kg}$ ), atendidos no Serviço de Diagnóstico por Imagem do HOVET - USP, São Paulo, Novembro de 2006.

Tabela 5 - $\quad$ Medidas da próstata de cães do Grupo 2 (animais com idade entre 31 e 60 meses), Subgrupo 5 (peso entre 11 e $25 \mathrm{~kg}$ ), atendidos no Serviço de Diagnóstico por Imagem do HOVET - USP, São Paulo, Novembro de 2006

Tabela 6 - Medidas da próstata de cães do Grupo 2 (animais com idade entre 31 e 60 meses), Subgrupo 6 (peso entre 11 e $25 \mathrm{~kg}$ ), atendidos no Serviço de Diagnóstico por Imagem do HOVET - USP, São Paulo, Novembro de 2006 


\section{LISTA DE GRÁFICOS}

Gráfico 1 - Comparação entre os valores médios de largura (L), comprimento (C) e altura (A) da próstata dos cães dos grupos $\mathbf{G 1}$ (até 30 meses) e $\mathbf{G 2}$ (de 31 a 60 meses), atendidos no Serviço de Diagnóstico por Imagem do HOVET/USP - São Paulo, Novembro de 2006.

Gráfico 2 - Comparação entre diferentes faixas de peso corpóreo dos valores médios de largura (L), comprimento $(\mathrm{C})$ e altura $(\mathrm{A})$ da próstata dos cães do Grupo 1 (até 30 meses de idade), atendidos no Serviço de Diagnóstico por Imagem do HOVET/USP - São Paulo, Novembro de 2006

Gráfico 3 - Comparação entre diferentes faixas de peso corpóreo dos valores médios de largura (L), comprimento $(\mathrm{C})$ e altura $(\mathrm{A})$ da próstata dos cães do Grupo 2 (de 31 a 60 meses de idade), atendidos no Serviço de Diagnóstico por Imagem do HOVET/USP - São Paulo, Novembro de 2006

Gráfico 4 - $\quad$ Ajuste das medidas, comprimento e largura, obtidas pelo exame ultrasonográfico da próstata dos cães examinados no Grupo 1 HOVET/USP, São Paulo, Novembro de 2006

Gráfico 5 - Ajuste das medidas, largura e altura, obtidas pelo exame ultrasonográfico da próstata dos cães examinados no Grupo 1 HOVET/USP, São Paulo, Novembro de 2006.

Gráfico 6 - Ajuste das medidas, comprimento e altura, obtidas pelo exame ultrasonográfico da próstata dos cães examinados no Grupo 1 HOVET/USP, São Paulo, Novembro de 2006.

Gráfico 7 - Ajuste das medidas, comprimento e largura, obtidas pelo exame ultrasonográfico da próstata dos cães examinados no Grupo 2 HOVET/USP, São Paulo, Novembro de 2006.

Gráfico 8 - Ajuste das medidas, largura e altura, obtidas pelo exame ultrasonográfico da próstata dos cães examinados no Grupo 2 HOVET/USP, São Paulo, Novembro de 2006.

Gráfico 9 - Ajuste das medidas, comprimento e altura, obtidas pelo exame ultrasonográfico da próstata dos cães examinados no Grupo 2 HOVET/USP, São Paulo, Novembro de 2006. 


\section{LISTA DE QUADROS}

Quadro 1 - Dados dos Grupos e Subgrupos dos animais selecionados, atendidos no Setor de Ultra-som do Serviço de Diagnóstico por Imagem do HOVET/USP - São Paulo, Novembro de 2006....................................... 43 


\section{LISTA DE ABREVIATURAS E SIGLAS}

$\begin{array}{ll}\text { A } & \text { altura } \\ \mathrm{C} & \text { comprimento } \\ \mathrm{cm} & \text { centímetro } \\ \mathrm{G} & \text { grupo } \\ \mathrm{HPB} & \text { hiperplasia prostática benigna } \\ \mathrm{kg} & \text { quilograma(s) } \\ \mathrm{L} & \text { largura } \\ \mathrm{MHz} & \text { mega hertz }\end{array}$


LISTA DE SÍMBOLOS

$=\quad$ igual $\mathrm{a}$

- multiplicado por

$\% \quad$ porcentagem 


\section{SUMÁRIO}

$2.1 \quad$ PRÓSTATA: ANATOMIA E MORFOLOGIA ................................... 26

2.2 PRÓSTATA: TÉCNICAS DE DIGANÓSTICO POR IMAGEM......... 29

2.3 PRÓSTATA: ABORDAGEM ULTRA-SONOGRÁFICA.................... 33

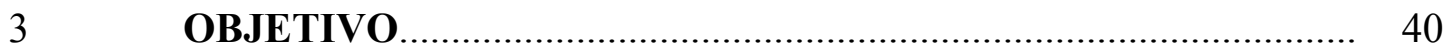

$4 \quad$ MATERIAL E MÉTODO.................................................... 42

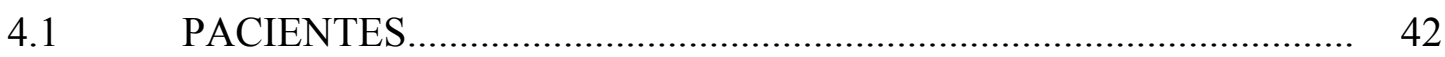

4.2 GRUPOS EXPERIMENTAIS......................................................... 43

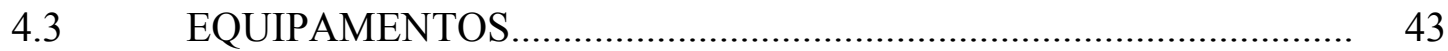

4.4 TÉCNICA DE EXAME ULTRA-SONOGRÁFICO........................... 44

E.5 EXAME ULTRA-SONOGRÁFICO.............................................. 44

4.5.1 Interpretação e Diagnóstico Ultra-sonográfico.............................. 45

4.6 ANÁLISE ESTATÍSTICA......................................................... 45

$5 \quad$ RESULTADOS

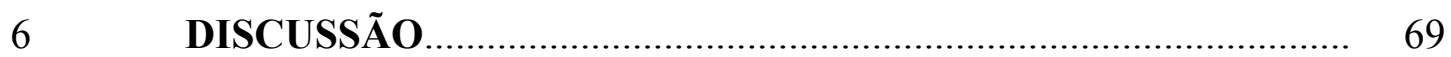

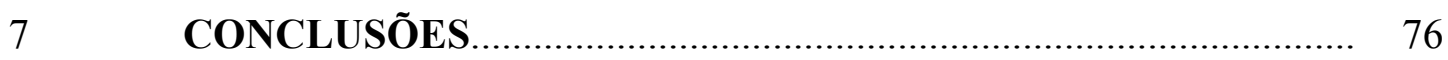

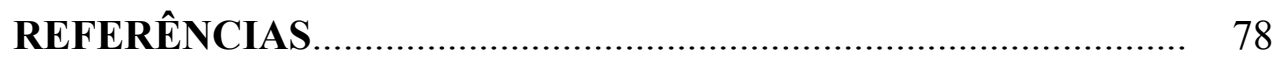

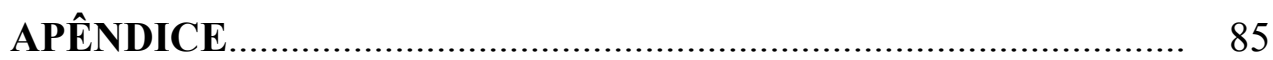


INTRODUÇÃO 


\section{INTRODUÇÃO}

A próstata, considerada a única glândula sexual acessória em cães, é um órgão bilobado com septo mediano na superfície dorsal (BARSANTI; FINCO, 1992).

A posição da próstata na porção caudal do abdômen depende da idade, distensão da bexiga e grau da doença prostática (BARSANTI; FINCO, 1992). Quando a vesícula urinária está vazia e contraída, a glândula está inteiramente na cavidade pélvica a $2,5 \mathrm{~cm}$ ou mais da borda anterior do púbis no sentido cranial. Quando a bexiga está repleta, a próstata projeta-se cranialmente localizando-se essencialmente na região pré-púbica.

A maioria das doenças prostáticas está associada à prostatomegalia. A avaliação do tamanho da próstata é um fator importante para o acompanhamento da evolução das doenças prostáticas em cães, e esta avaliação, normalmente é realizada pela palpação retal, exame radiográfico e ultra-sonografia abdominal (RUEL et al., 1998). A palpação retal é um simples método pelo qual se faz a avaliação do tamanho da próstata, mas que permite apenas o exame da porção dorsal ou dorso-caudal da glândula. Outro exame simples, para a mensuração do tamanho da próstata é o exame radiográfico. No entanto, os limites prostáticos podem não ser identificados por influência da sobreposição dos outros órgãos, como o cólon descendente (KAMOLPATANA et al., 2000). As técnicas radiográficas são úteis para detectar tamanho, forma e localização da glândula prostática. No entanto, a visualização radiográfica de lesões não é específica, não há como diferenciar as alterações de hiperplasia, infecção e neoplasia (ATALAN; BARR; HOLT, 1999a). 
Tanto a palpação retal como o exame radiográfico podem ser utilizados para identificar prostatomegalia, mas o exame ultra-sonográfico permite uma melhor avaliação qualitativa, podendo identificar mudanças na arquitetura parenquimatosa (GREEN; HONCO, 1996), permitindo a diferenciação entre lesões císticas e sólidas (ZEKAS et al., 2004), classificando, muitas vezes, as principais doenças que acometem este órgão. Em função da localização da próstata, a melhor forma para a avaliação ultra-sonográfica desta glândula em cães, é a abordagem supra-púbica. Apesar do protocolo de avaliação ultrasonográfica da próstata do homem recomendar a abordagem transretal, sua aplicação em medicina veterinária torna-se inviável em função da combinação de dois fatores: a anatomia da uretra do cão e a variedade do tamanho dos pacientes (FEENEY; JOHNSTON; KLAUSTER, 1985). Jia et al. (2005), realizou um trabalho de mensuração prostática através da ressonância magnética enfatizando a importância da contínua realização de trabalhos em torno do assunto.

A próstata apresenta um aspecto ultra-sonográfico homogêneo, com uma ecogenicidade superior a dos rins, porém, inferior a do baço. Vários pontos pequenos anecogênicos aparecem por todo o parênquima, de forma homogênea. A próstata é um órgão de fácil acesso para o exame ultrasonográfico o qual fornece informações importantes de sua estrutura, constituindo um método rápido e auxiliar na determinação do diagnóstico de prostatopatias (BOMASSI; TESTAULT; ROUSSELOT, 2002).

Os dados referentes às medidas da próstata foram encontrados na literatura revisada de uma maneira ampla e generalizada, porém trabalhos recentes exibem justamente a preocupação com o estabelecimento do 
parâmetro ultra-sonográfico de normalidade. Diante do exposto, torna-se clara a necessidade da realização de pesquisas que visem verificar a existência ou não de relação entre massa corpórea de cães e os valores de comprimento, altura e largura da próstata medida pela técnica ultra-sonográfica transabdominal (ATALAN; BARR; HOLT, 1999b; NYLAND; MATOON, 2002; MURASHIMA, 2001; SCHAEFFTER, 2000). 
REVISÃO DA LITERATURA 


\section{REVISÃO DA LITERATURA}

O exame ultra-sonográfico apresenta algumas vantagens, em relação a outros métodos de diagnóstico por imagem, que contribuem para sua crescente utilização em medicina veterinária (GREEN, 1996). Pelo exame ultrasonográfico pode-se realizar uma avaliação estrutural parenquimatosa de maneira não invasiva da glândula prostática do cão (PENNICK, 1998).

\subsection{PRÓSTATA: ANATOMIA E MORFOLOGIA}

A próstata constitui-se na única glândula sexual acessória presente na espécie canina, caracterizada por ser uma estrutura músculo-glandular de formato longitudinal arredondado ou ovalado e de formato transversal bilobado, apresentando dois sulcos sagitais medianos, um dorsal e outro ventral (ELLENPORT, 1981; EVANS, 1993). Está localizada predominantemente no espaço retroperitoneal, caudalmente à bexiga. Somente a face craniodorsal está coberta pelo peritônio. A próstata circunda a uretra proximal no colo da bexiga, e seus ductos penetram na uretra ao longo de toda a sua circunferência (BARSANTI; FINCO, 1992). Ela ainda estabelece relação anatômica com outros órgãos abdominais. O reto encontra-se dorsal à mesma e a parede ventral do abdômen assim como a sínfese do púbis está localizada ventralmente (CRISTHENSEN; EVANS, 1964).

Seu posicionamento em relação à cavidade é determinado pela repleção vesical, maturidade sexual e pelas doenças que acometem o órgão (ELLENPORT, 1981; EVANS, 1993). Após a perda do úraco remanescente 
(antes de dois meses de idade), a próstata passa a se localizar no interior da entrada da pelve. Com o aumento da idade, a próstata novamente tende a tomar localização abdominal, de forma que nos machos caninos não castrados com mais de cinco anos de idade, a maior parte da próstata apresenta localização abdominal (BARSANTI; FINCO, 1992). Quadros patológicos alteram a topografia prostática devido às variações de massa, dimensões e simetria por eles ocasionadas. Tal alteração também decorre de afecções adjacentes à próstata (extra-prostáticas), tais como: linfoadenopatias regionais, hérnias perineais, neoplasias e distúrbios neuro-motores no cólon (JOHNSTON et al., 1991).

A próstata do cão apresenta-se levemente achatada dorsalmente, sendo dividida por um septo mediano, que a torna bilobada e bilateralmente simétrica (BARSANTI; FINCO, 1992). As trabeculações oriundas da cápsula, que se estendem pelo parênquima, dividem seus lobos em lóbulos (NYLAND; MATOON, 2002), constituídos por glândulas túbulo-alveolares, cujos ductos convergem para a uretra prostática, totalmente envolta pelo tecido glandular. (EVANS, 1993).

A despeito do grande número de estudos centrados na estrutura da próstata do cão, as funções fisiológicas da glândula permanecem pouco compreendidas. Embora as secreções prostáticas sirvam de veículo para os espermatozóides, as secreções podem não ser essenciais para a fertilidade (BASSINGER et al., 1993). Sob o estímulo parassimpático que ocorre durante a ereção, a próstata aumenta a taxa de produção de líquido, e sob o estímulo simpático, expulsa o líquido durante a ejaculação (BARSANTI; FINCO, 1992). 
Entre os quatro e dezesseis meses de idade, cães da raça Beagle apresentam um crescimento da glândula constante e duplicado. Este crescimento corresponde ao período em que a testosterona sérica aumenta até alcançar o nível adulto normal. Uma vez que a próstata atinge o seu tamanho adulto normal (12 a $14 \mathrm{~g}$ nos cães da raça Beagles), o seu crescimento é interrompido (BARSANTI; FINCO, 1992). O'Shea (1962), ao estudar a próstata de 154 cães, determinou a idade média para ocorrência de HPB como sendo de 9 anos. Se um cão for castrado antes de atingir a maturidade sexual, então o crescimento prostático normal fica completamente inibido. Se um cão for castrado após atingir a maturidade sexual, a próstata involuirá $20 \%$ do seu tamanho normal. Com o envelhecimento, ocorre aumento aparente do crescimento da glândula prostática. Assim, à medida que o cão envelhece, a glândula prostática aumenta em volume (BARSANTI; FINCO, 1992).

Uma das causas mais comuns de aumento da glândula prostática em cães é a hiperplasia prostática benigna (HPB) (GUIDO, 2004). Mais que $80 \%$ dos cães com idade superior a cinco anos, machos, não castrados possuem alterações histológicas compatíveis com HPB (SIRINARUMITR, 2001), sendo que aproximadamente $80 \%$ dos machos caninos com idade superior a 10 anos desenvolvem alguma doença prostática (BOLAND et al., 2003).

Segundo Selcer (1995), a próstata de indivíduos não castrados (inteiros) sofre influência anabólica da testosterona sintetizada e secretada pelas gônadas, sendo maiores que aquelas de cães orquiectomizados, que apresentam uma atrofia característica. Esse fato as caracteriza como glândulas andrógeno-dependentes ou andrógeno-responsivas. 
A incidência de doenças prostáticas é de $2,5 \%$ em toda a população de cães machos, e este valor pode atingir $8 \%$ quando é analisada uma população de cães com idade acima de 10 anos (KRAWIEC, 1994). Com o amadurecimento, a próstata aumenta de volume gradualmente devido à hiperplasia. Devido à natureza glandular deste órgão, podem se desenvolver cistos líquidos prostáticos pelo parênquima, em associação com a hiperplasia. As alterações prostáticas também podem estar associadas a doenças em outros órgãos, seja por doenças sistêmicas, seja por doenças associadas ao trato gênito-urinário, como sertoliomas funcionais causando hiperestrogenismo. (BARSANTI; FINCO, 1992).

\subsection{PRÓSTATA: TÉCNICAS DE DIAGNÓSTICO POR IMAGEM}

O tamanho da próstata pode ser avaliado mediante palpação retal, radiografia, ultra-sonografia, tomografia computadorizada e ressonância magnética (ATALAN et al., 1999c). O diagnóstico das afecções da próstata requer informações provenientes do histórico do paciente, exame físico e clínico, auxiliados pelos exames laboratoriais e pelas técnicas de diagnóstico por imagem (radiografia, ultra-sonografia, tomografia computadorizada e ressonância magnética). No exame físico do paciente, a palpação retal tem destaque na veterinária, devendo ser prática no exame de rotina em todo e qualquer macho da espécie canina, uma vez que se presta a realizar uma triagem para os casos de prostatopatias (ATALAN; BARR; HOLT, 1999a).

O cão é o único animal doméstico cuja próstata, quando aumentada, é visível no exame radiográfico (LATTIMER, 1986). Radiografias simples do 
abdômen caudal possibilitam a avaliação de tamanho, silhueta e localização da próstata, que apresenta forma ovóide, e radiopacidade homogênea de tecidos moles (FEENEY et al., 1987a). A próstata é freqüentemente distinguível nas projeções latero-lateral e dorsoventral no exame radiográfico da porção caudal do abdômen. A glândula normal é simétrica, com contornos lisos, e está localizada próxima a borda cranial do assoalho pélvico (BARSANTI; FINCO, 1992). A radiografia simples realizada com o animal em decúbito latero-lateral é um excelente método para avaliação da glândula quando esta está aumentada, porém, de pouco auxílio diagnóstico quando a mesma apresenta-se com seu tamanho normal (ACKERMAN, 1991).

O exame ultra-sonográfico é uma técnica de imagem valiosa que complementa o radiodiagnóstico das afeç̧ões prostáticas (FEENEY et al., 1987b). Apresenta outras vantagens, por se tratar de um método não invasivo e não ionizante (PETER; JAKOVLJEVIC, 1992), podendo, portanto, ser realizado em curtos períodos de tempo e por repetidas vezes (BLUM et al, 1985). Permite também, a monitorização do paciente frente à terapia instituída (CARTEE et al., 1990).

Outras técnicas de diagnóstico por imagem, como tomografia computadorizada e a ressonância magnética também são técnicas não invasivas, porém, de alto custo e na maioria das vezes, animais anestesiados (HERRING, 1985).

A imagem ultra-sonográfica da próstata normal revela um parênquima com ecogenicidade homogênea, geralmente hipoecogênica com relação aos tecidos adjacentes (GUIDO, 2004). Os lobos prostáticos não podem ser identificados individualmente. A forma bilobada da próstata pode ser 
visualizada em imagem ultra-sonográfica realizando-se um corte transversal (NYLANDTOON, 1995).

As informações obtidas com o exame ultra-sonográfico da próstata são estritamente morfológicas, não possibilitando qualquer estudo funcional, porém revela mais informações a respeito da estrutura glandular, de linfoadenopatias regionais e uma melhor identificação do parênquima prostático em comparação com as técnicas radiográficas (FEENEY; JOHNSTON; WALTER, 1991). No estudo prostático, a técnica ultra-sonográfica é inquestionavelmente superior à técnica radiográfica, pois oferece mais informações sobre a estrutura geral, tamanho, formato, e arquitetura interna (FEENEY; JOHNSTON; WALTER, 1991).

Quando as técnicas radiográficas e ultra-sonográficas são comparadas na mensuração da próstata, observa-se que as medidas do comprimento são semelhantes (ATALAN et al., 1999c), porém a ultra-sonografia fornece medidas mais acuradas e confiáveis, principalmente quanto aos contornos prostáticos que se apresentam melhor definidos sem efeito de magnificação da imagem, em comparação ao exame radiográfico (RUEL et al., 1998). Ainda, as mensurações são realizadas com a utilização de marcadores eletrônicos integrados, estimando-se medidas mais precisas. Embora o exame ultrasonográfico seja considerado a técnica de eleição no estudo prostático, os exames radiográficos simples e contrastados não devem ser abandonados, e sim, utilizados como ferramenta complementar diagnóstica na avaliação desta glândula (NYLAND; MATTOON, 2002).

O exame ultra-sonográfico da próstata permite a avaliação da uretra prostática que pode ser visualizada no corte transversal. Ela aparece como 
uma estrutura hipoecóica ou anecóica na região central da próstata. A uretra se encontra normalmente colabada, porém, é possível visualizar seu lúmen quando esta se encontra dilatada por um conteúdo urinário anecóico. No corte longitudinal, ela forma uma estrutura linear em continuidade ao colo vesical (MAÏ, 2002). Exames radiográficos com contraste positivo, como a uretrocistografia retrógrada, são complementares para o diagnóstico diferencial entre prostatomegalia e cistos paraprostáticos, bem como, para avaliação da uretra prostática (FEENEY et al., 1987b). Tal exame deve ser considerado principalmente, para a abordagem diagnóstica do paciente disúrico (MARTINS, 2003).

O Doppler Colorido tem sido muito utilizado como técnica não invasiva para a avaliação da arquitetura vascular da próstata em humanos, assim como, na avaliação da vascularização em tumores prostáticos, e para diferenciar as neoplasias prostáticas dos processos benignos que afetam a próstata do homem (NEWELL et al., 1998).

Em trabalho realizado com 16 cães, sendo 11 com próstatas normais e cinco com prostatite linfocítica, utilizando-se o Doppler Colorido, Newell et al. (1998) estabeleceram os padrões de normalidade deste exame para a próstata canina, porém concluíram que estudos adicionais são necessários para que o mesmo possa auxiliar na avaliação clínica das doenças prostáticas em cães. 


\subsection{PRÓSTATA: ABORDAGEM ULTA-SONOGRÁFICA}

O animal deve ser posicionado em decúbito dorsal (GUIDO, 2004) ou lateral (GREEN; HOMCO, 1996; JONHSTON et al; 1991). Os autores afirmam que a abordagem pode variar em função de preferências individuais, porém, deve ser cuidadosa para evitar omissões.

A tricotomia é preconizada na região pré-púbica (FEENEY et al., 1987b), porém, a próstata normalmente é avaliada juntamente com os demais órgãos abdominais, sendo necessária uma ampla tricotomia no abdômen entre a região epigástrica e hipogástrica, compreendida entre o apêndice xifóide e os dois últimos pares de glândulas mamárias, estendendo-se lateralmente na região ventral aos músculos lombares, próximos ao último par de costelas do lado esquerdo e sobre os dois últimos pares de costelas do lado direito (GUIDO, 2004).

A utilização de gel apropriado é indicada em toda a literatura consultada (ATALAN; BARR; HOLT, 1999a; ATALAN; BARR; HOLT, 1999b; CARTEE; ROWLES, 1983; CARTEE et al., 1990; FEENEY et al., 1987a; GUIDO, 2004; PETER et al., 1992)

A repleção vesical tem grande importância, pois ela proporciona a formação da janela acústica adequada ao deslocar as vísceras repletas por gases da região de acesso e por tracionar a próstata cranialmente, eliminando assim, a interferência das estruturas ósseas da pelve (ATALAN; BARR; HOLT, 1999a; ATALAN; BARR; HOLT, 1999b; CARTEE; ROWLES, 1983; GREEN; HOMCO, 1996; NYLAND; MATOON, 2002; PETER et al., 1992; ROOT; SPAULDING, 1994). Uma pequena dose de diurético, tal como furosemida, 
administrado por via endovenosa, pode ser utilizado para causar repleção da bexiga durante o exame (NYLAND; MATOON, 2002).

Para se realizar as medidas do órgão podem-se utilizar os transutores de 5,0 ou 7,5 MHz. Devem ser realizadas imagens no plano longitudinal e transversal através da próstata, sendo que o osso peniano dificulta a realização das medidas transversais (GUIDO, 2004). Nyland e Matoon (2002) indicam o uso de transdutores de freqüência 7,5 ou $10 \mathrm{MHz}$, quando possível, pois consideram que transdutores de freqüência de $5,0 \mathrm{MHz}$ ou de freqüências inferiores podem não oferecer resolução adequada e não permitir a observação de pequenas lesões focais e de alterações discretas do parênquima.

O acesso abdominal é o que melhor se presta à avaliação da margem glandular cranial, fornecendo, todavia, menor riqueza de detalhes da cápsula posterior. Em contrapartida, a porção caudal da próstata é mais bem avaliada por via transretal, além de mostrar-se como um acesso mais sensível na detecção de alterações de ecogenicidade do parênquima. Contudo, a referida técnica não é muito difundida na espécie canina em virtude do custo do equipamento, necessidade de transdutores de diversos tamanhos e pela grande variação de porte na espécie (ZOHIL; CASTELLANO, 1995).

Holm e Northved (1974) citam a técnica transuretral como excelente método de avaliação da próstata no homem, porém a complexidade anatômica da uretra canina restringe sua utilização na prática veterinária.

Em relação ao aspecto ultra-sonográfico, a próstata apresenta formato simétrico, de arredondado a oval em corte longitudinal e bilobado em corte transversal (ACKERMAN, 1991; ATALAN; BARR; HOLT, 1999b; ATALAN et al., 1999c; BARR, 1990; CARTEE et al., 1990; COONEY; CARTEE; RUMPH, 
1992; DUGRAGNE E BEGON, 1996; FEENEY et al., 1985; GREEN; HOMCO, 1996; JOHNSTON et al., 1991; NYLAND; MATOON, 2002; RUEL et al., 1998; SELCER et al., 1995).

A uretra prostática pode ser avaliada quando se encontra dilatada (BARR, 1990; GREEN; HOMCO, 1996). Quando esta não apresenta dilatação, pode ser observada pela imagem em corte transversal e descrita como uma área central hipoecogênica envolvida por uma área hiperecogênica, que apresenta além da uretra prostática os ductos periuretrais. Seu aspecto pode variar dependendo da idade do animal, freqüência do transdutor, presença ou ausência de doenças prostáticas atuais ou prévias, e até pelo tipo de processamento de imagens do equipamento utilizado (CARTEE et al., 1990; CARTEE, 1995; DUGRAGNE; BEGON, 1996; FEENEY et al., 1985; GREEN; HOMCO, 1996; JOHNSTON et al., 1991; LATTIMER, 1986; NYLAND; MATOON, 2002).

A escolha do transdutor depende do porte do paciente. Transdutores de 5,0 e 7,5 MHz são os mais recomendados, pois permitem um campo visual de $90^{\circ}$ assegurando avaliação completa da glândula (JOHNSTON et al., 1991; MUZZI et al., 1997).

Para a mensuração prostática, são realizados cortes transversais e longitudinais, sendo que o corte longitudinal é perfeitamente adquirido quando se observa uma imagem hipoecogênica da uretra prostática (RUEL et al., 1998). O comprimento corresponde à máxima distância crânio-caudal da glândula, no eixo uretral. A altura é o maior diâmetro perpendicular ao eixo do comprimento. Após esta avaliação é indicado que o transdutor seja rotacionado em $90^{\circ}$ para que então, se obtenham imagens transversais da próstata. Nesse 
corte, no plano transversal, a altura é considerada como a máxima distância dorso-ventral da próstata na linha que separa os dois lobos glandulares, e a largura, o maior diâmetro perpendicular a essa medida (GUIDO, 2004; RUEL et al., 1998).

Um dos primeiros estudos ultra-sonográficos da próstata de cães, foi realizado por Cartee e Rowles (1983), com o objetivo de determinar a precisão desta técnica na mensuração da glândula. Para tanto, foram utilizados oito cães normais e quatro com prostatomegalia, pesando entre 7 e $30 \mathrm{~kg} \mathrm{e} \mathrm{com}$ idade entre 2 e 4 anos. Foram obtidas imagens em corte longitudinal, onde $o$ comprimento foi considerado como a distância máxima entre as margens cranial e caudal e a determinação da altura foi obtida, como aquela perpendicular ao eixo longitudinal da próstata, ou seja, perpendicular ao trajeto uretral. As margens cranial e caudal foram mais facilmente delimitadas em função da presença de urina na bexiga e uretra prostática, e as margens dorsal e ventral foram mais difíceis de serem determinadas por estarem próximas a estruturas de impedância acústica muito similar a próstata.

Lattimer (1986), considera importante, para a avaliação da próstata normal do cão, comparar a mensuração ultra-sonográfica da próstata com a medida radiográfica do espaço intra pélvico. Ele afirma que o valor do diâmetro da próstata, obtido pela mensuração ultra-sonográfica não pode ser maior do que a metade da largura do espaço intra pélvico, em radiografia ventro-dorsal.

Atalan, Barr e Holt (1999a) e Feeney et al. (1987a), compararam a medida ultra-sonográfica da próstata com a medida radiográfica obtida entre o promontório do osso sacro até a borda do púbis. Neste trabalho, os autores concluíram que a próstata pode ser considerada aumentada se a mensuração 
ultra-sonográfica, exceder a $70 \%$ da distância do promontório do osso sacro até a borda do púbis, obtida pela mensuração radiográfica.

As medidas consideradas normais para a próstata do cão variam de acordo com peso, raça e idade do animal (GUIDO, 2004).

Cartee et al (1990), realizaram um estudo de mensuração da glândula prostática em 25 cães da raça Beagle de idade entre 5 e 6 anos e peso médio de $12 \mathrm{~kg}$. As medidas foram obtidas pelo exame ultra-sonográfico e foram utilizados transdutores de 5,0 e $10 \mathrm{MHz}$. Os valores médios obtidos de comprimento e largura foram respectivamente: $2,02 \mathrm{~cm} \mathrm{e} \mathrm{2,76} \mathrm{cm.}$

Utilizando animais com idade abaixo de 5 anos e com peso entre 11 e $30 \mathrm{~kg}$, alguns autores chegaram a valores parecidos quando da mensuração prostática pelo exame ultra-sonográfico. Kamolpatana et al. (2000), obtiveram as seguintes medidas da próstata: comprimento $3,15 \mathrm{~cm}( \pm 0,83 \mathrm{~cm})$, largura $3,15 \mathrm{~cm}( \pm 0,9 \mathrm{~cm})$ e altura $2,83 \mathrm{~cm}( \pm 0,6 \mathrm{~cm})$. Ruel et al. (1998), obtiveram medidas semelhantes: comprimento $3,4 \mathrm{~cm}( \pm 1,1 \mathrm{~cm})$, largura $3,3 \mathrm{~cm}( \pm 0,9 \mathrm{~cm})$ e altura $2,8 \mathrm{~cm}( \pm 0,8 \mathrm{~cm})$.

Schaeffter (2000), na avaliação ultra-sonográfica para padronização da medida prostática normal de 26 cães da raça Pastor Alemão, com idade entre 1 e 7 anos, pesando entre 27 e $48 \mathrm{~kg}$ obteve as seguintes medidas: em corte longitudinal, comprimento médio de $3,59 \mathrm{~cm}$, e altura média de $3,45 \mathrm{~cm}$; em corte transversal, largura média de $4,63 \mathrm{~cm}$ e altura média de $3,28 \mathrm{~cm}$.

Murashima (2001) trabalhou, em seu estudo, com mensuração da próstata por ultra-sonografia, e sua associação com a massa corpórea de cães adultos e clinicamente sadios, com idade entre 12 e 48 meses. Para tal, dividiu seus pacientes em três grupos: Grupo 1, animais pesando entre 2,0 e 6,0 kg; 
Grupo 2, animais pesando entre 7,0 e 15,0 kg e Grupo 3, animais pesando entre 22,0 e $57,0 \mathrm{~kg}$. Os resultados obtidos no Grupo 1 foram: comprimento $2,01 \mathrm{~cm}$, altura $2,05 \mathrm{~cm}$ e largura $2,38 \mathrm{~cm}$. No Grupo 2, as medidas obtidas foram: comprimento $2,35 \mathrm{~cm}$, altura $2,06 \mathrm{~cm}$ e largura $2,51 \mathrm{~cm}$. No Grupo 3, as medidas obtidas foram: comprimento $3,18 \mathrm{~cm}$, altura $3,06 \mathrm{~cm}$ e largura 3,45 $\mathrm{cm}$.

Santos et al. (2004), realizaram um estudo para mensuração ultrasonográfica do aparelho reprodutor de cães da raça Dogue Alemão. O objetivo do estudo foi medir in vivo as dimensões dos testículos, epidídimos e próstata destes cães. A medida média da próstata foi $4,04 \mathrm{~cm}( \pm 0,91 \mathrm{~cm})$ de comprimento e 4,00 cm $( \pm 0,91 \mathrm{~cm})$ de largura. 
OBJETIVO 


\section{OBJETIVO}

Este trabalho teve por objetivo determinar, por meio do exame ultrasonográfico, o valor médio de comprimento, largura e altura da próstata de cães clinicamente sadios, de diferentes idades e pesos, para a padronização das medidas normais desta glândula. 
MATERIAL E MÉTODO 


\section{MATERIAL E MÉTODO}

Os pacientes deste estudo eram oriundos do Hospital Veterinário (HOVET) da Faculdade de Medicina Veterinária e Zootecnia da Universidade de São Paulo (FMVZ-USP), e foram encaminhados ao Serviço de Diagnóstico por Imagem (ultra-sonografia) do mesmo hospital no período de março de 2005 a janeiro de 2006.

\subsection{PACIENTES}

Foram utilizados cães, machos, hígidos, com idade entre 12 e 60 meses, encaminhados ao Setor de Ultra-som para a realização de exames ultra-sonográficos. Os fatores de exclusão dos pacientes no referido estudo foram:

1) animais que apresentassem ausência de testículo em bolsa escrotal (monorquídicos, anorquídicos e criptorquídicos)

2) animais que apresentassem alterações ecográficas do parênquima prostático no momento da realização do exame.

Incluíram-se apenas os animais com a próstata considerada normal, cuja imagem ultra-sonográfica revelou parênquima com ecogenicidade homogênea e hipoecogênica com relação aos tecidos adjacentes, conforme descreveu Guido (2004).

Além da ausência de qualquer sintoma relacionado ao trato genitourinário, estes animais também foram avaliados pelos seguintes exames complementares: hemograma completo e urinálise. 
Para cada paciente foi aberto um protocolo para identificação do animal e anotações dos dados coletados pelo exame ultra-sonográfico da próstata (Apêndice A).

\subsection{GRUPOS EXPERIMENTAIS}

Os animais incluídos neste estudo foram divididos segundo a idade em dois grupos (G1 e G2). E cada um deles foi subdividido conforme o peso corporal em três subgrupos. Neste estudo, foi possível incluir 47 cães. 0 Quadro 1 apresenta as subdivisões dos grupos 1 e 2 (G1 e G2), bem como o número de animais em cada grupo.

\begin{tabular}{|c|c|c|c|c|c|c|}
\hline \multirow{2}{*}{$\begin{array}{c}\text { GRUPOS } \\
\text { SUBGRUPOS } \\
\text { (PESOS) }\end{array}$} & \multicolumn{3}{|c|}{$\begin{array}{c}\text { G1 } \\
\text { (animais com até } 30 \text { meses) }\end{array}$} & \multicolumn{3}{|c|}{$\begin{array}{c}\text { G2 } \\
\text { (animais entre } 31 \text { e } 60 \text { meses) }\end{array}$} \\
\hline & $\begin{array}{c}1 \\
\text { Até } 10 \mathrm{~kg}\end{array}$ & $\begin{array}{c}2 \\
11 \text { a } 25 \mathrm{~kg}\end{array}$ & $\begin{array}{c}3 \\
\text { Acima de } 25 \mathrm{~kg}\end{array}$ & $\begin{array}{c}4 \\
\text { Até } 10 \mathrm{~kg}\end{array}$ & $\begin{array}{c}5 \\
11 \text { a } 25 \mathrm{~kg}\end{array}$ & $\begin{array}{c}6 \\
\underset{\text { Acima de }}{25 \mathrm{~kg}} \\
\end{array}$ \\
\hline Número de cães & 7 & 7 & 7 & 11 & 9 & 6 \\
\hline
\end{tabular}

Quadro 1 - Dados dos Grupos e Subgrupos dos animais selecionados, atendidos no Setor de Ultra-som do Serviço de Diagnóstico por Imagem do HOVET/USP - São Paulo, Novembro de 2006

\subsection{EQUIPAMENTOS}

Para realização dos exames ultra-sonográficos foi utilizado o aparelho de ultra-sonografia TOKIMEC CS-3030 (figura 1) empregando-se os transdutores linear de 7,5 MHz e convexo de 5,0 MHz (figura 4), conforme o porte do animal. 
A escolha da freqüência a ser utilizada foi de grande importância para a obtenção de imagens de boa definição, sendo que a freqüência adequada está diretamente relacionada ao tamanho do animal a ser examinado (SCHAEFFTER, 2000).

A documentação fotográfica dos exames das próstatas foi gravada em impressora Sony, modelo UP-895MD (figura 2). Nos exames foi utilizado gel para ultra-som abdominal e torácico (Multigel@ Ltda).

\subsection{TÉCNICA DE EXAME ULTRA-SONOGRÁFICO}

Após ampla tricotomia da região abdominal, os animais foram posicionados em decúbito dorsal e lateral. O gel foi aplicado sobre a superfície da pele como manobra fundamental para a realização do exame ultra-sonográfico. Inicialmente, investigava-se a bexiga, linfonodos e demais órgãos abdominais, em busca de possíveis alterações extra prostáticas que fossem motivo para exclusão de pacientes no referido estudo. Uma vez descartadas tais alterações, procedia-se o exame detalhado da próstata.

\subsection{EXAME ULTRA-SONOGRÁFICO DA PRÓSTATA}

Inicialmente foram avaliadas as características do parênquima prostático e quando não constatadas alterações nos contornos, na ecogenicidade e na ecotextura, realizavam-se as medidas prostáticas. Foram obtidas medidas das distâncias dorso-ventral, crânio-caudal e laterolateral. Para a altura foi feita a medida dorso-ventral (figuras 10 e 12) e para 
o comprimento a medida crânio-caudal (figuras 10 e 12), ambas em plano ultra-sonográfico longitudinal (figuras 8 e 9) e para a largura a medida laterolateral da próstata (figura 7 e 11) em plano ultra-sonográfico transversal (figuras 5 e 6$)$.

\subsubsection{Interpretação e Diagnóstico Ultra-sonográfico}

As medidas ultra-sonográficas das próstatas foram avaliadas e descritas em fichas individuais a ser interpretadas dentro de cada grupo (apêndice A).

\subsection{ANÁLISE ESTATÍSTICA}

Em cada subgrupo foi calculada a média das medidas de largura, comprimento e altura e mostrado o seu desvio padrão. Para verificar a existência de correlação entre as medidas encontradas em cada subgrupo foi calculado o coeficiente de correlação entre elas. Para tal estudo estatístico foi utilizado o Teste ANOVA com nível de significância de 5\%. 


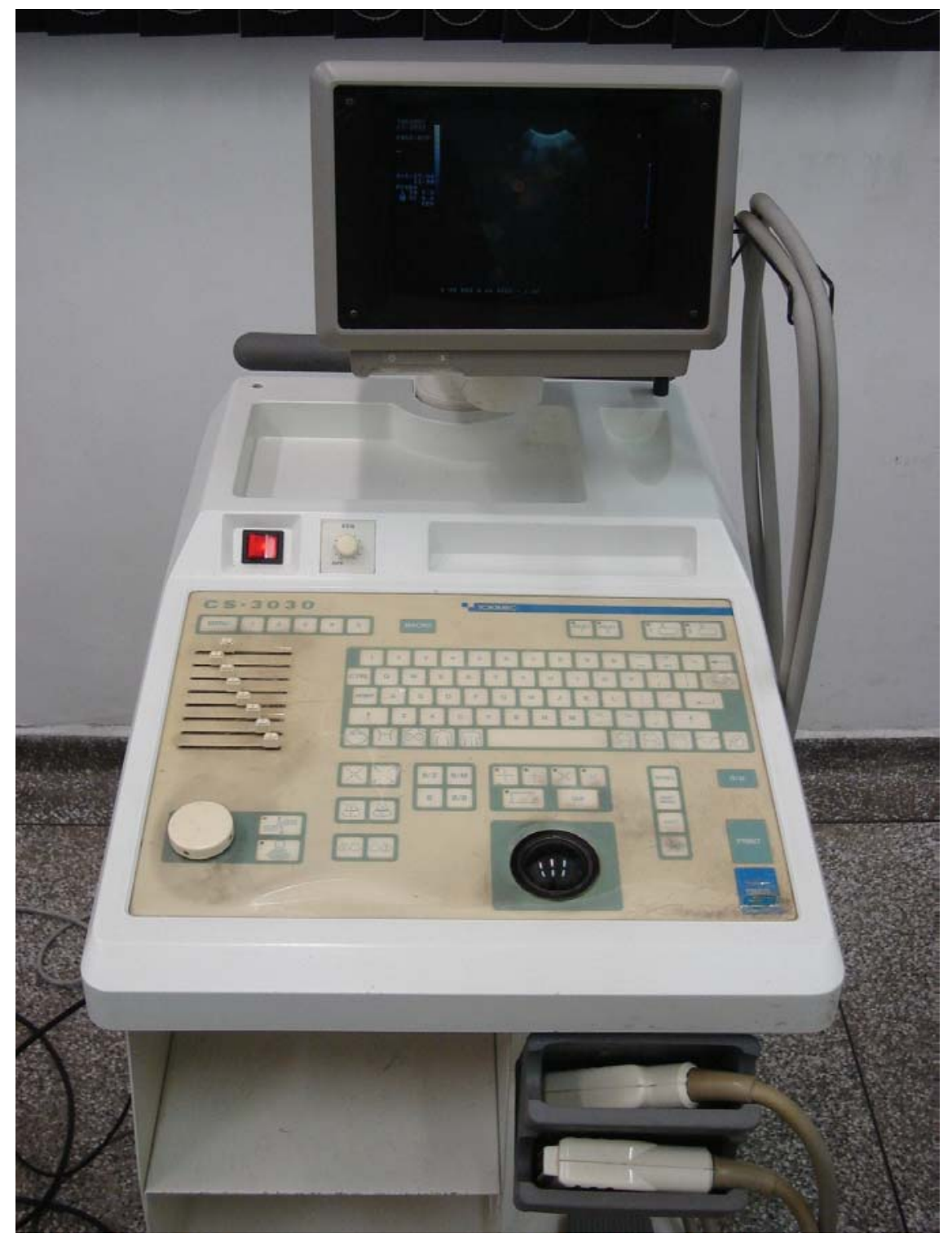

Figura 1- Aparelho de ultra-sonografia TOKIMEC CS-3030, utilizado para avaliação ultrasonográfica dos pacientes, e mensuração das próstatas - FMVZ/USP - São Paulo, Novembro de 2006

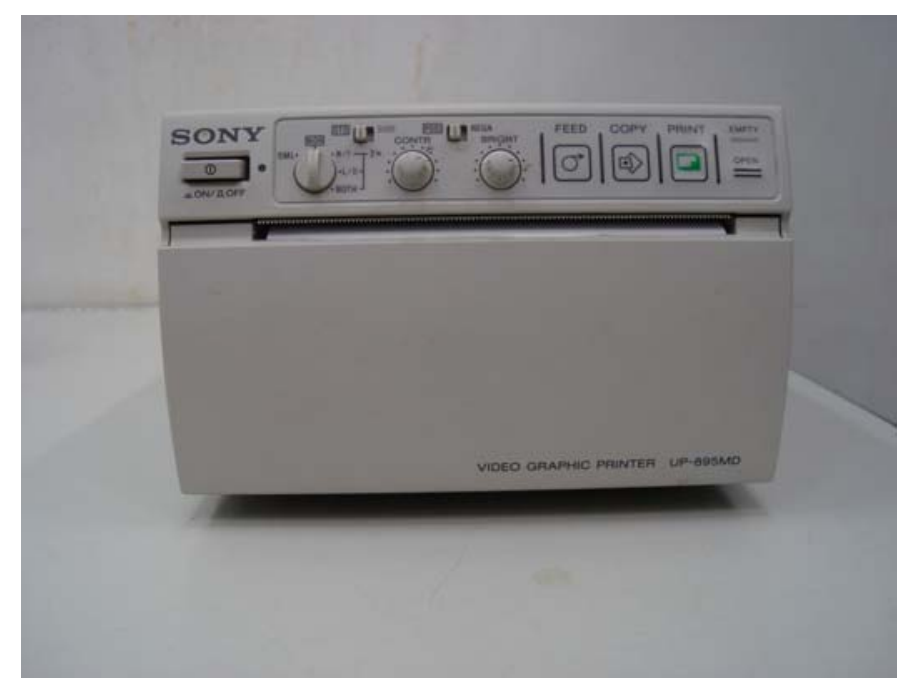

Figura 2 - Impressora Sony, modelo UP-895MD - FMVZ/USP - São Paulo, Novembro de 2006 


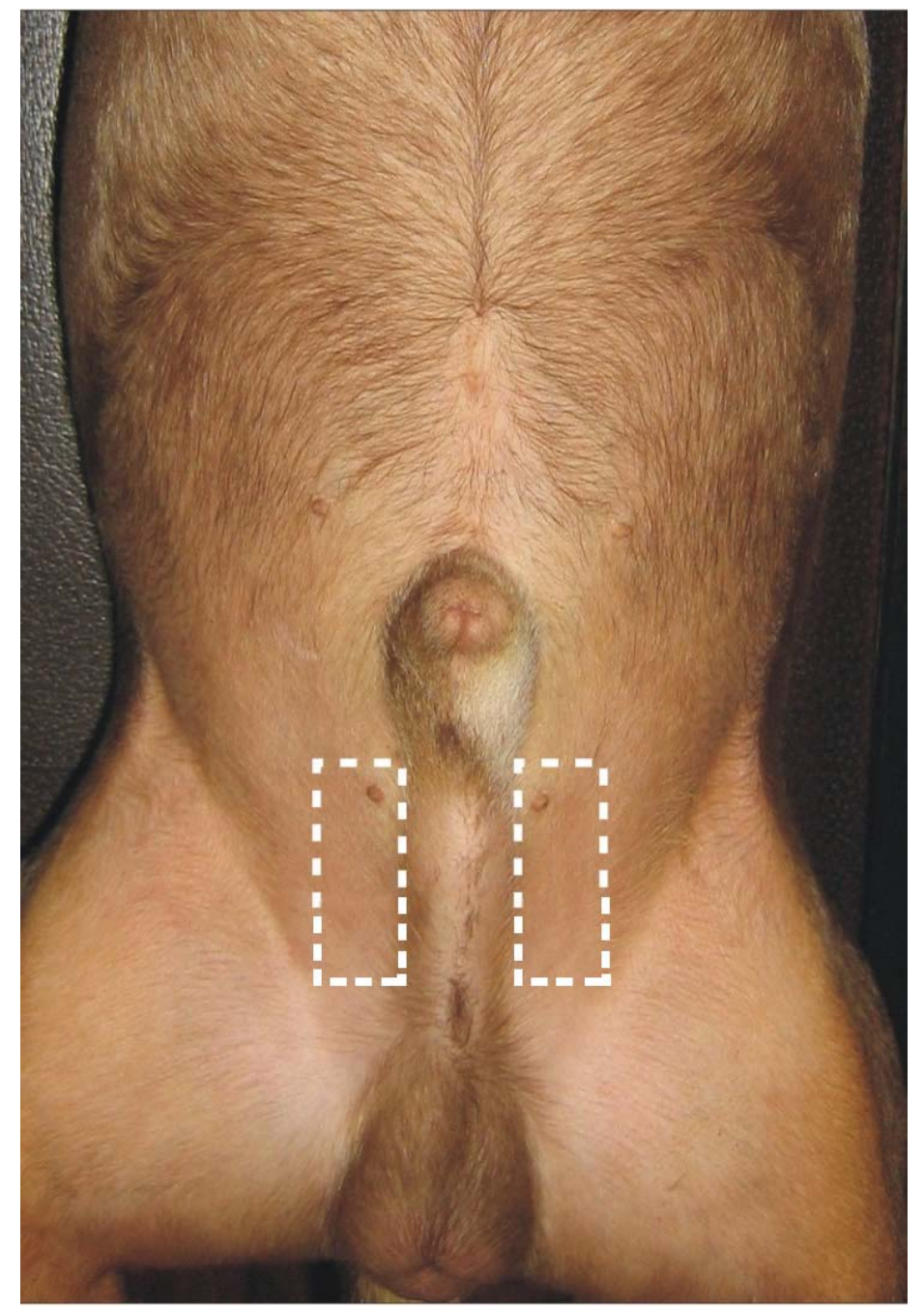

Figura 3 - Localização de acesso ultra-sonográfico transabdominal à próstata do cão - FMVZ/USP São Paulo, Novembro de 2006

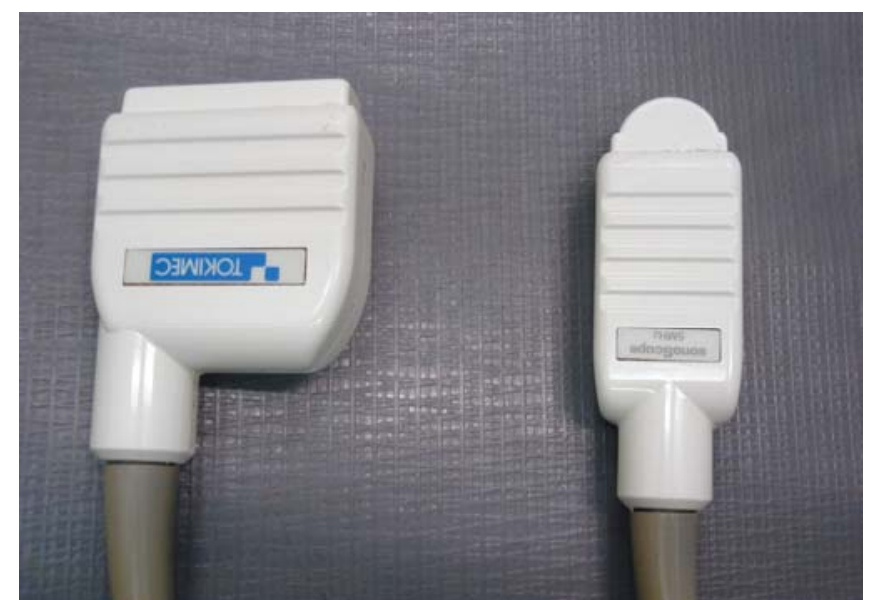

Figura 4 - Transdutores linear de 7,5 MHz (esquerda) e convexo de 5,0 MHz (direita) utilizados para avaliação ultra-sonográfica da próstata canina - FMVZ/USP - São Paulo, Novembro de 2006 

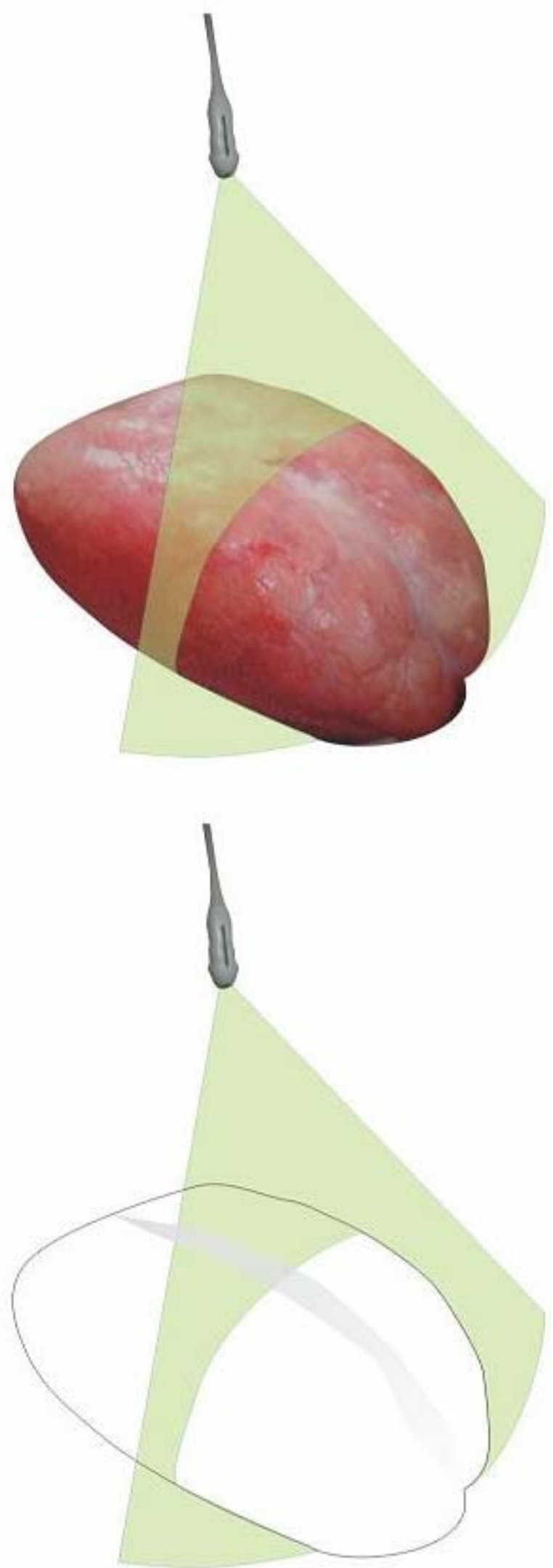

Figura 5 - Plano transversal de varredura na avaliação ultra-sonográfica da próstata canina FMVZ/USP - São Paulo, Novembro de 2006 


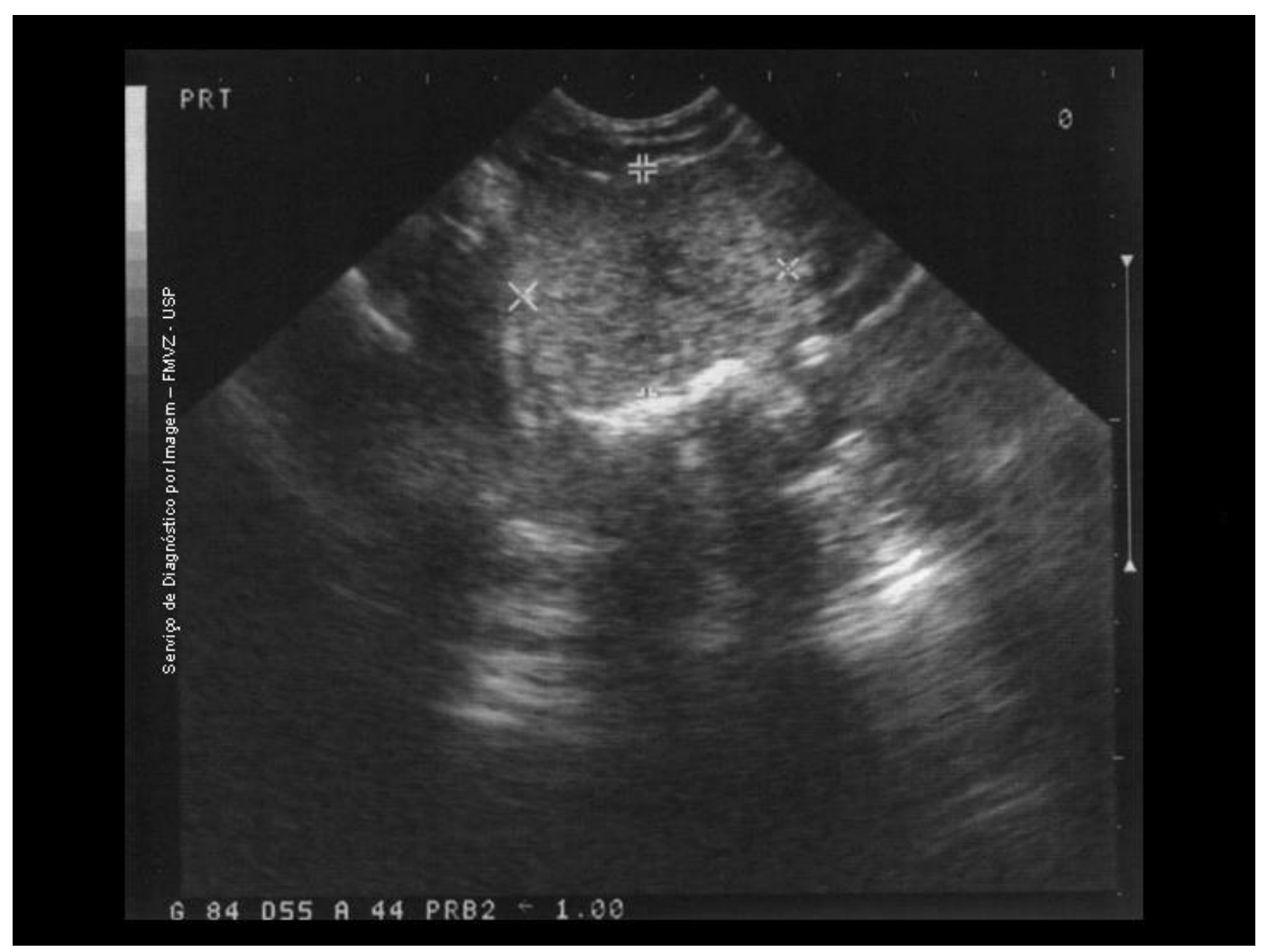

Figura 6 - Imagem ultra-sonográfica de próstata normal em cão, corte transversal - FMVZ/USP São Paulo, Novembro de 2006

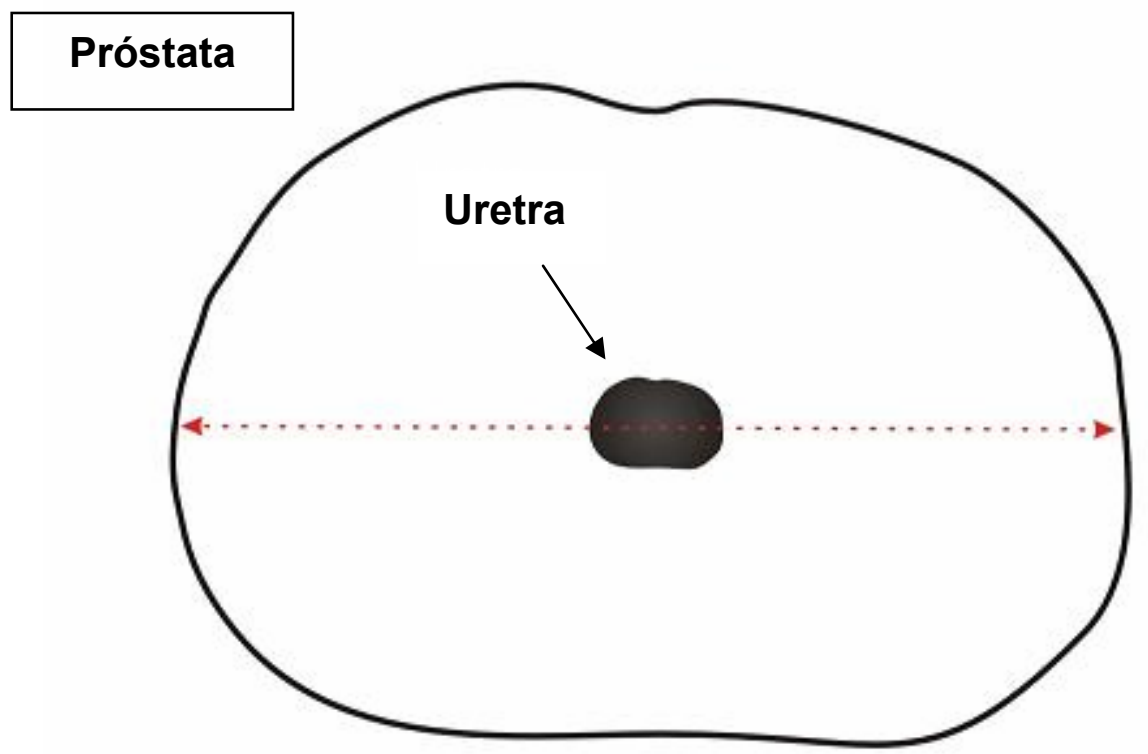

Figura 7 - Desenho esquemático da medida latero-lateral da próstata canina no exame ultrasonográfico, corte transversal - FMVZ/USP - São Paulo, Novembro de 2006 

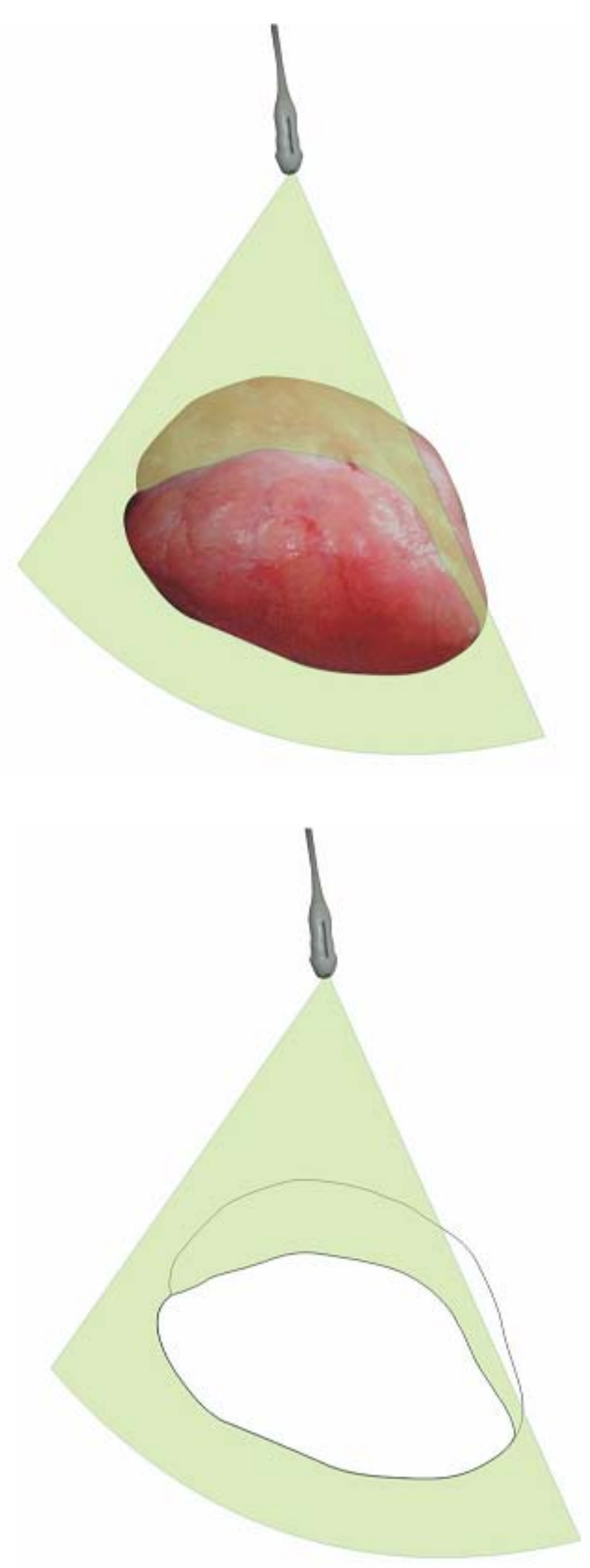

Figura 8 - Plano longitudinal de varredura na avaliação ultra-sonográfica da próstata canina FMVZ/USP - São Paulo, Novembro de 2006 


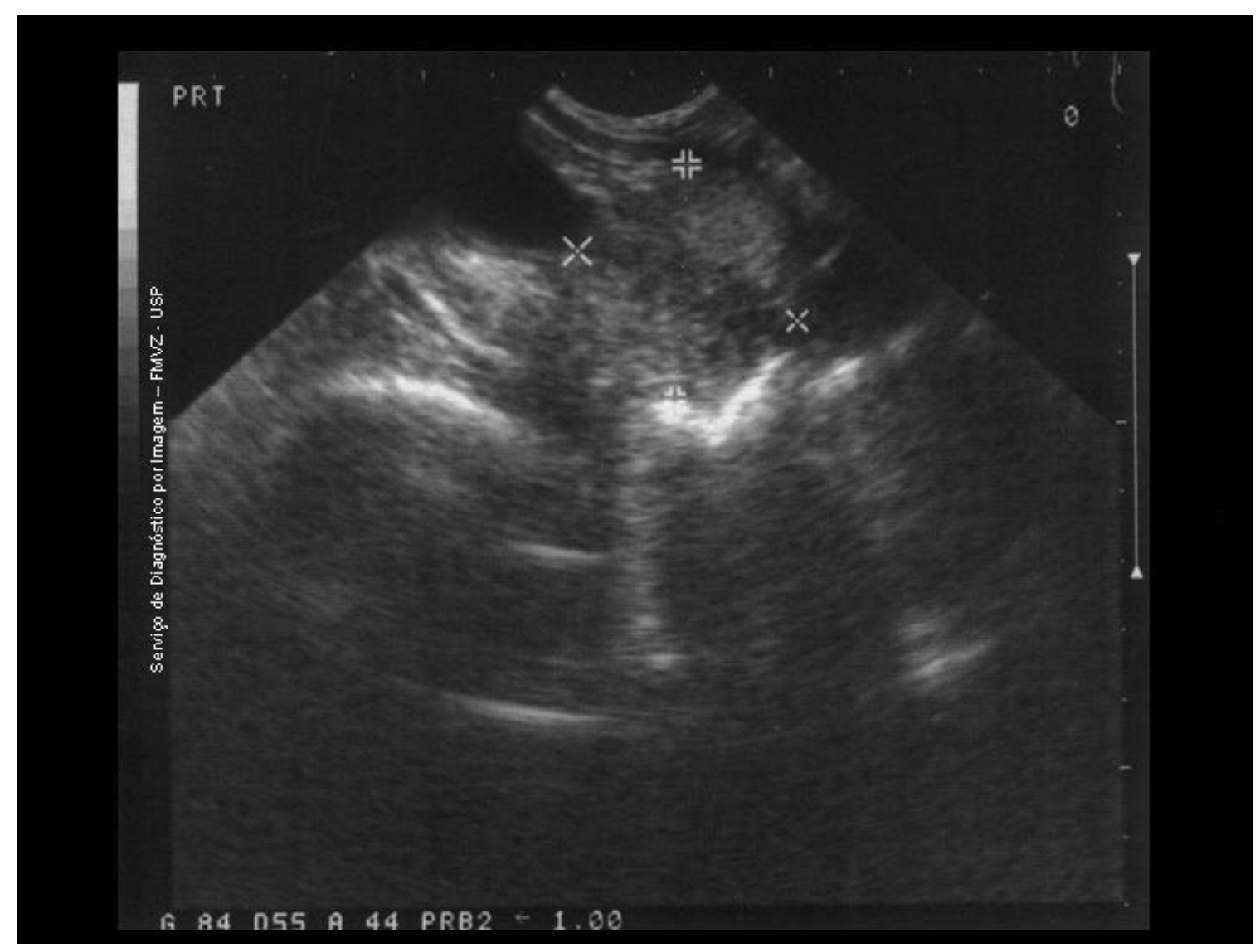

Figura 9 - Imagem ultra-sonográfica de próstata normal em cão, corte longitudinal - FMVZ/USP São Paulo, Novembro de 2006

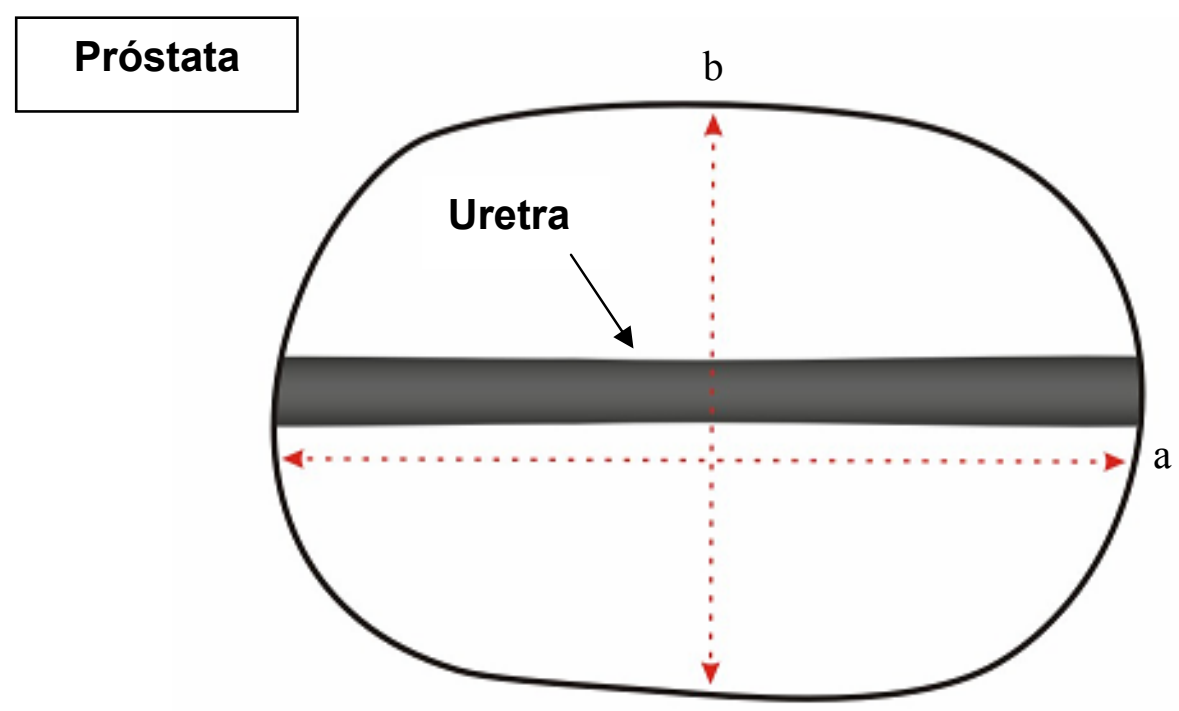

Figura 10 - Desenho esquemático das medidas crânio-caudal (a) e dorso-ventral (b) da próstata canina no exame ultra-sonográfico, corte longitudinal - FMVZ/USP - São Paulo, Novembro de 2006 


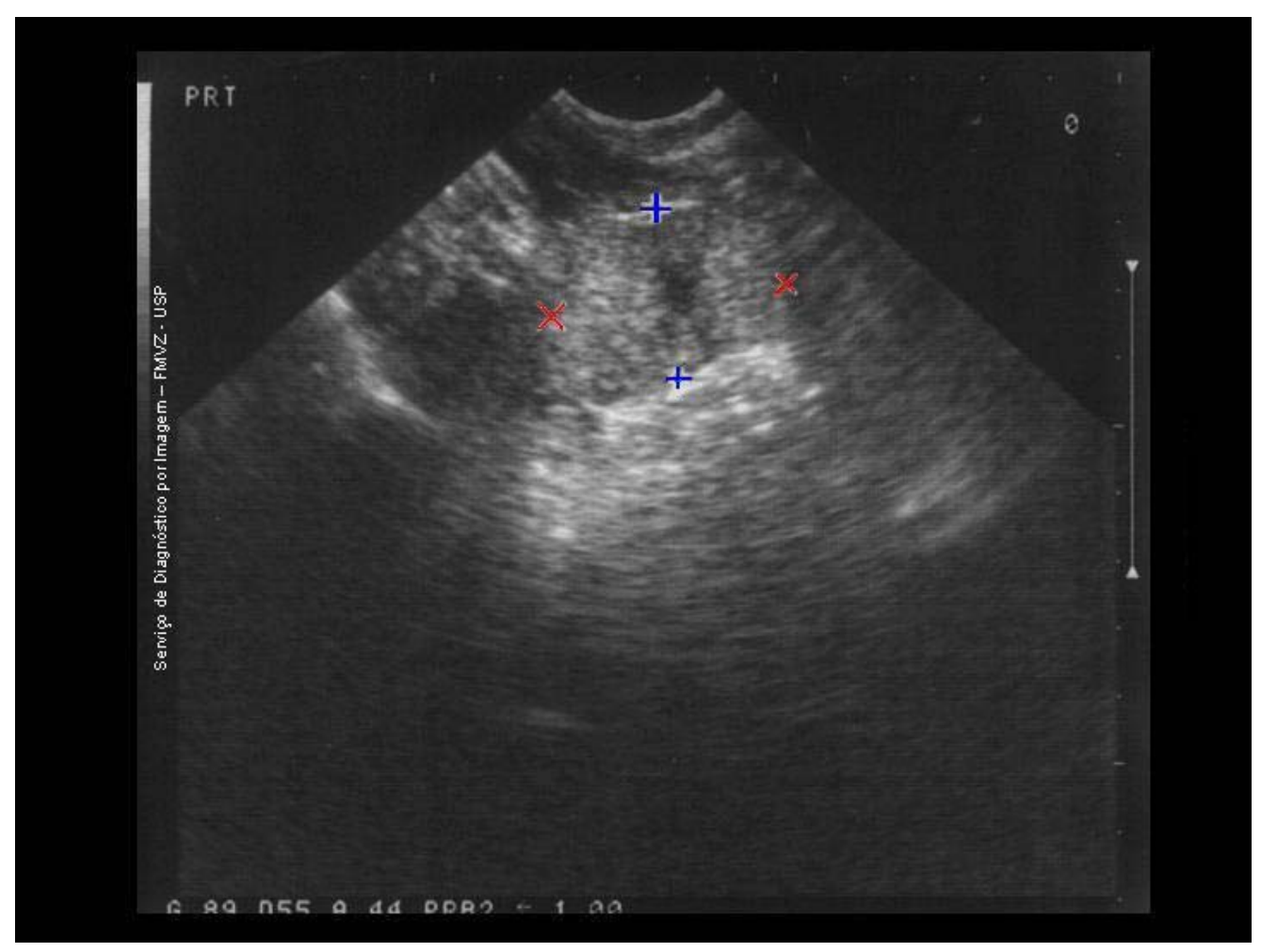

Figura 11 - Imagem ultra-sonográfica da próstata canina normal, em corte transversal identificando as medidas de: largura, latero $(\mathrm{X})$ - lateral $(\mathrm{X})$ e altura, dorso (+) - ventral (+) - FMVZ/USP - São Paulo, Novembro de 2006

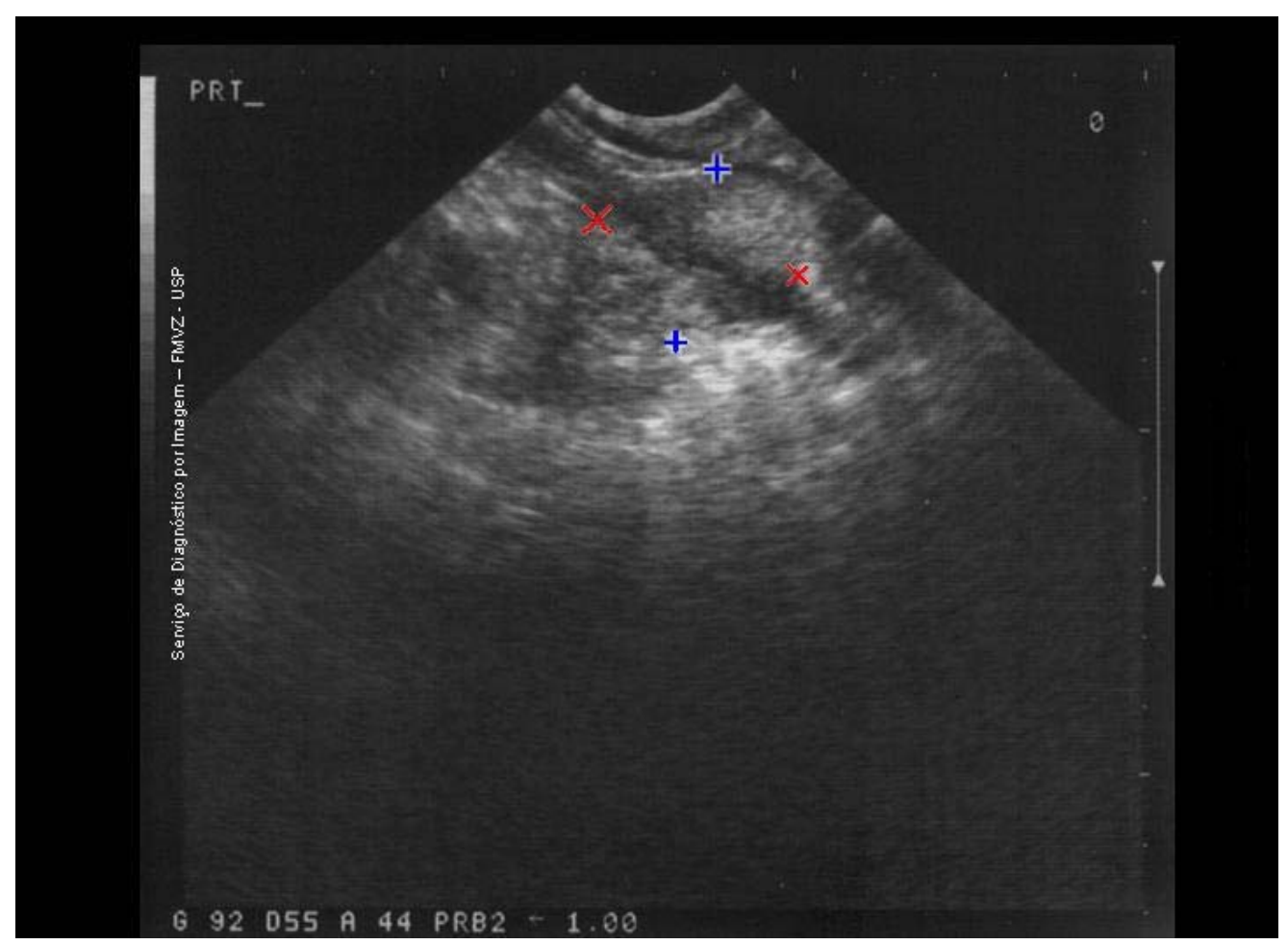

Figura 12 - Imagem ultra-sonográfica da próstata canina normal, em corte longitudinal identificando as medidas de: comprimento, crânio $(X)$ - caudal $(X)$ e altura, dorso (+) - ventral (+) - FMVZ/USP - São Paulo, Novembro de 2006 
RESULTADOS 


\section{RESULTADOS}

Foram realizados exames ultra-sonográficos em quarenta e sete cães de diferentes raças com idade entre um e cinco anos, para a avaliação da próstata.

5.1 Características ultra-sonográficas da próstata: topografia, ecogenicidade e arquitetura.

Em todos os animais examinados, a localização da próstata foi em região caudal à bexiga na posição retroperitoneal.

Nos exames realizados, a próstata foi visualizada com ecogenicidade homogênea, hiperecogênica com relação ao baço e hipoecogênica com relação aos tecidos adjacentes.

Na imagem ultra-sonográfica, a próstata sempre apresentou um formato simétrico de contornos regulares e definidos.

O corte longitudinal permitiu a mensuração adequada do comprimento e da altura (figura 12). A largura foi obtida da imagem de corte transversal (figura 11). Os resultados referentes à largura, comprimento e altura, com suas médias e respectivos desvios padrão apresentam-se nas tabelas 1 a 6. 
Tabela 1 - $\quad$ Medidas da próstata de cães do Grupo 1 (animais com idade até 30 meses), Subgrupo 1 (peso até $10 \mathrm{~kg}$ ), atendidos no Serviço de Diagnóstico por Imagem do HOVET-USP, São Paulo, Novembro de 2006

\begin{tabular}{|c|c|c|c|}
\hline Indivíduo & Largura (cm) & Comprimento (cm) & Altura (cm) \\
\hline 1 & 1,2 & 1,0 & 1,0 \\
\hline 2 & 1,3 & 1,1 & 1,0 \\
\hline 3 & 1,2 & 1,1 & 1,1 \\
\hline 4 & 1,7 & 1,4 & 1,4 \\
\hline 5 & 1,4 & 1,2 & 1,2 \\
\hline 6 & 1,3 & 1,1 & 1,1 \\
\hline 7 & 1,8 & 1,4 & 1,5 \\
\hline Média & 1,41 & 1,19 & 1,17 \\
\hline Desvio Padrão & 0,24 & 0,16 & 0,20 \\
\hline
\end{tabular}


Tabela 2 - Medidas da próstata de cães do Grupo 1 (animais com idade até 30 meses), Subgrupo 2 (peso entre 11 e 25 $\mathrm{kg}$ ), atendidos no Serviço de Diagnóstico por Imagem do HOVET - USP, São Paulo, Novembro de 2006

\begin{tabular}{|c|c|c|c|}
\hline Indivíduo & Largura (cm) & Comprimento $(\mathrm{cm})$ & Altura (cm) \\
\hline 8 & 2,6 & 2,1 & 2,1 \\
\hline 9 & 2,5 & 2,1 & 1,9 \\
\hline 10 & 2,5 & 2,1 & 1,8 \\
\hline 11 & 2,8 & 2,4 & 2,2 \\
\hline 12 & 2,8 & 2,1 & 2,1 \\
\hline 13 & 2,7 & 2,2 & 2,0 \\
\hline 14 & 2,6 & 2,2 & 2,2 \\
\hline Média & 2,64 & 2,17 & 2,04 \\
\hline Desvio Padrão & 0,13 & 0,11 & 0,15 \\
\hline
\end{tabular}


Tabela 3 - $\quad$ Medidas da próstata de cães do Grupo 1 (animais com idade até 30 meses), Subgrupo 3 (peso acima de 25 $\mathrm{kg}$ ), atendidos no Serviço de Diagnóstico por Imagem do HOVET - USP, São Paulo, Novembro de 2006

\begin{tabular}{|c|c|c|c|}
\hline Indivíduo & Largura (cm) & Comprimento (cm) & Altura (cm) \\
\hline 15 & 3,3 & 2,8 & 2,7 \\
\hline 16 & 3,9 & 3,2 & 2,9 \\
\hline 17 & 3,4 & 2,9 & 2,6 \\
\hline 18 & 3,8 & 3,2 & 3,1 \\
\hline 19 & 3,7 & 3,0 & 3,0 \\
\hline 20 & 3,7 & 3,2 & 3,0 \\
\hline 21 & 3,6 & 3,3 & 3,2 \\
\hline Média & 3,63 & 3,09 & 2,93 \\
\hline Desvio Padrão & 0,21 & 0,19 & 0,21 \\
\hline
\end{tabular}


Tabela 4 - $\quad$ Medidas da próstata de cães do Grupo 2 (animais com idade entre 31 e 60 meses), Subgrupo 4 (peso até 10 $\mathrm{kg}$ ), atendidos no Serviço de Diagnóstico por Imagem do HOVET - USP, São Paulo, Novembro de 2006

\begin{tabular}{|c|c|c|c|}
\hline Indivíduo & Largura $(\mathrm{cm})$ & Comprimento(cm) & Altura $(\mathrm{cm})$ \\
\hline 22 & 2,5 & 2,1 & 2,0 \\
\hline 23 & 2,6 & 2,2 & 2,2 \\
\hline 24 & 2,5 & 2,2 & 2,1 \\
\hline 25 & 2,4 & 2,0 & 2,0 \\
\hline 26 & 2,7 & 2,4 & 2,4 \\
\hline 27 & 2,3 & 2,0 & 2,1 \\
\hline 28 & 2,4 & 2,0 & 1,9 \\
\hline 29 & 2,5 & 2,1 & 2,1 \\
\hline 30 & 3,0 & 2,1 & 2,1 \\
\hline 31 & 2,8 & 2,3 & 2,0 \\
\hline 32 & 2,8 & 2,1 & 2,1 \\
\hline Média & 2,59 & 2,14 & 2,12 \\
\hline Desvio Padrão & 0,21 & 0,13 & 0,16 \\
\hline
\end{tabular}


Tabela 5 - $\quad$ Medidas da próstata de cães do Grupo 2 (animais com idade entre 31 e 60 meses), Subgrupo 5 (peso entre 11 e $25 \mathrm{~kg}$ ), atendidos no Serviço de Diagnóstico por Imagem do HOVET - USP, São Paulo, Novembro de 2006

\begin{tabular}{|c|c|c|c|}
\hline Indivíduo & Largura $(\mathrm{cm})$ & Comprimento $(\mathrm{cm})$ & Altura $(\mathrm{cm})$ \\
\hline 33 & 4,0 & 3,7 & 3,5 \\
\hline 34 & 3,6 & 2,9 & 2,8 \\
\hline 35 & 3,1 & 2,9 & 2,8 \\
\hline 36 & 2,9 & 2,7 & 2,5 \\
\hline 37 & 3,0 & 2,4 & 2,4 \\
\hline 38 & 3,2 & 2,6 & 2,3 \\
\hline 39 & 3,1 & 2,7 & 2,5 \\
\hline 40 & 3,7 & 3,2 & 3,0 \\
\hline 41 & 3,0 & 2,2 & 2,8 \\
\hline Média & 3,29 & 2,81 & 3,73 \\
\hline Desvio Padrão & 0,38 & 0,44 & 0,37 \\
\hline
\end{tabular}


Tabela 6 - $\quad$ Medidas da próstata de cães do Grupo 2 (animais com idade entre 31 e 60 meses), Subgrupo 6 (peso entre 11 e $25 \mathrm{~kg}$ ), atendidos no Serviço de Diagnóstico por Imagem do HOVET - USP, São Paulo, Novembro de 2006

\begin{tabular}{cccc}
\hline Indivíduo & Largura (cm) & Comprimento (cm) & Altura (cm) \\
\hline 42 & 3,7 & 3,2 & 3,1 \\
\hline 43 & 4,4 & 4,0 & 4,0 \\
\hline 44 & 3,8 & 3,3 & 3,2 \\
\hline 45 & 4,3 & 3,7 & 3,5 \\
\hline 46 & 4,1 & 3,3 & 3,1 \\
\hline 47 & 3,9 & 3,3 & 3,2 \\
\hline Desvio Padrão & 0,28 & 3,47 & 0,35 \\
\hline Média & 4,03 & 0,31 & 3,35 \\
\hline
\end{tabular}

Quando comparados os valores médios entre as medidas de largura, comprimento e altura do G1 com as medidas do G2, observa-se que os cães com idade até 30 meses (G1) têm valores menores que os cães com idade entre 31 e 60 meses (G2) (gráfico 1). Utilizando-se o programa Excel para realização do teste qui-quadrado com nível de significância $5 \%$ obteve-se o 
resultado estatístico onde se observou que a diferença dos valores médios entre G1 e G2 não é significativa.

O mesmo foi realizado entre os Subgrupos de cada Grupo em relação à massa corpórea (gráfico 2 e 3), onde pode-se verificar que os cães de peso maior possuem valores médios de largura, comprimento e altura da próstata maiores que os animais de peso menor, porém, pela análise estatística, esta diferença não é significativa.

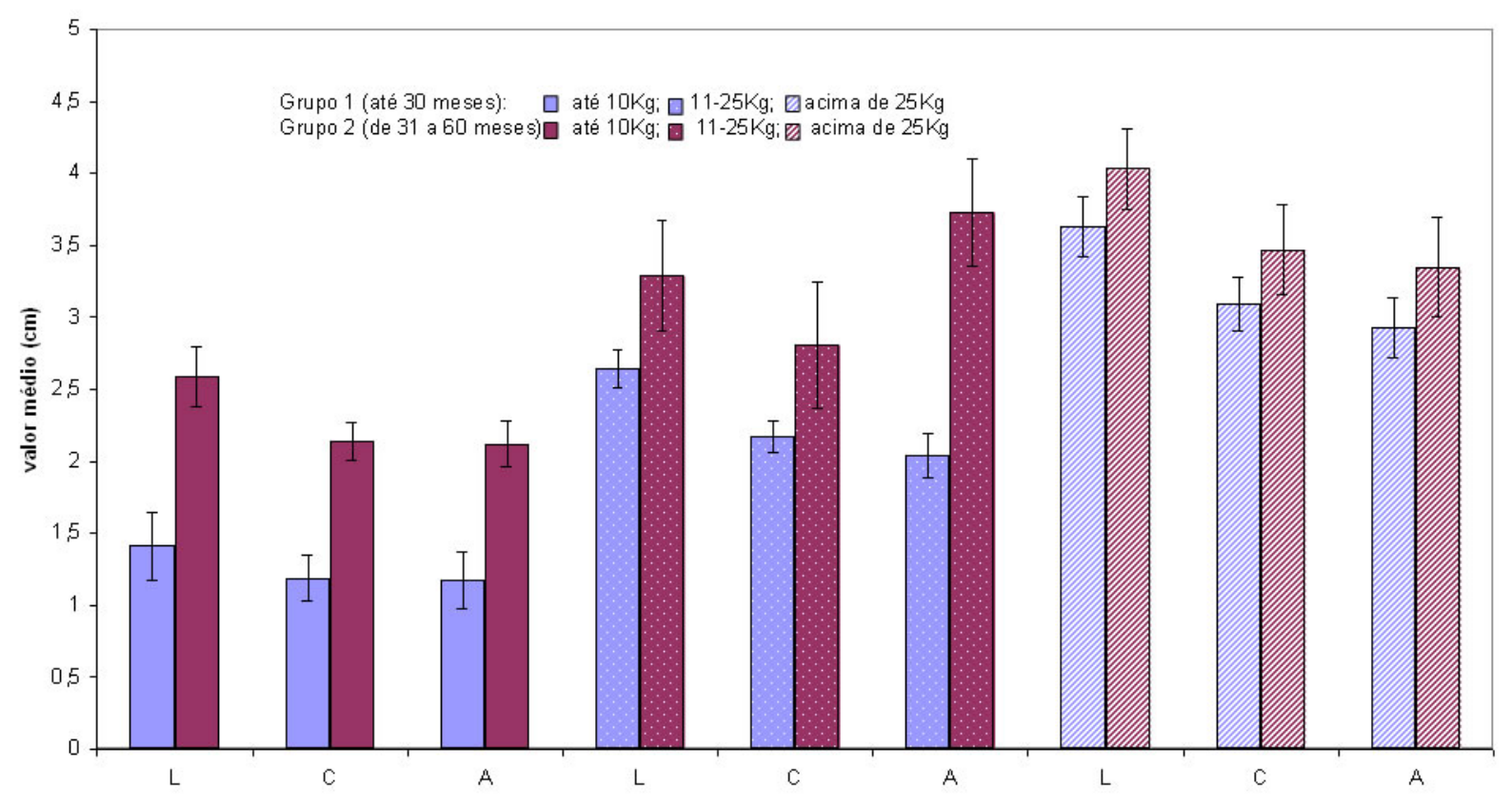

Gráfico 1 - Comparação entre os valores médios de largura $(\mathrm{L})$, comprimento $(\mathrm{C})$ e altura $(\mathrm{A})$ da próstata dos cães dos grupos $\mathbf{G 1}$ (até 30 meses) e $\mathbf{G} 2$ (de 31 a 60 meses), atendidos no Serviço de Diagnóstico por Imagem do HOVET/USP - São Paulo, Novembro de 2006 


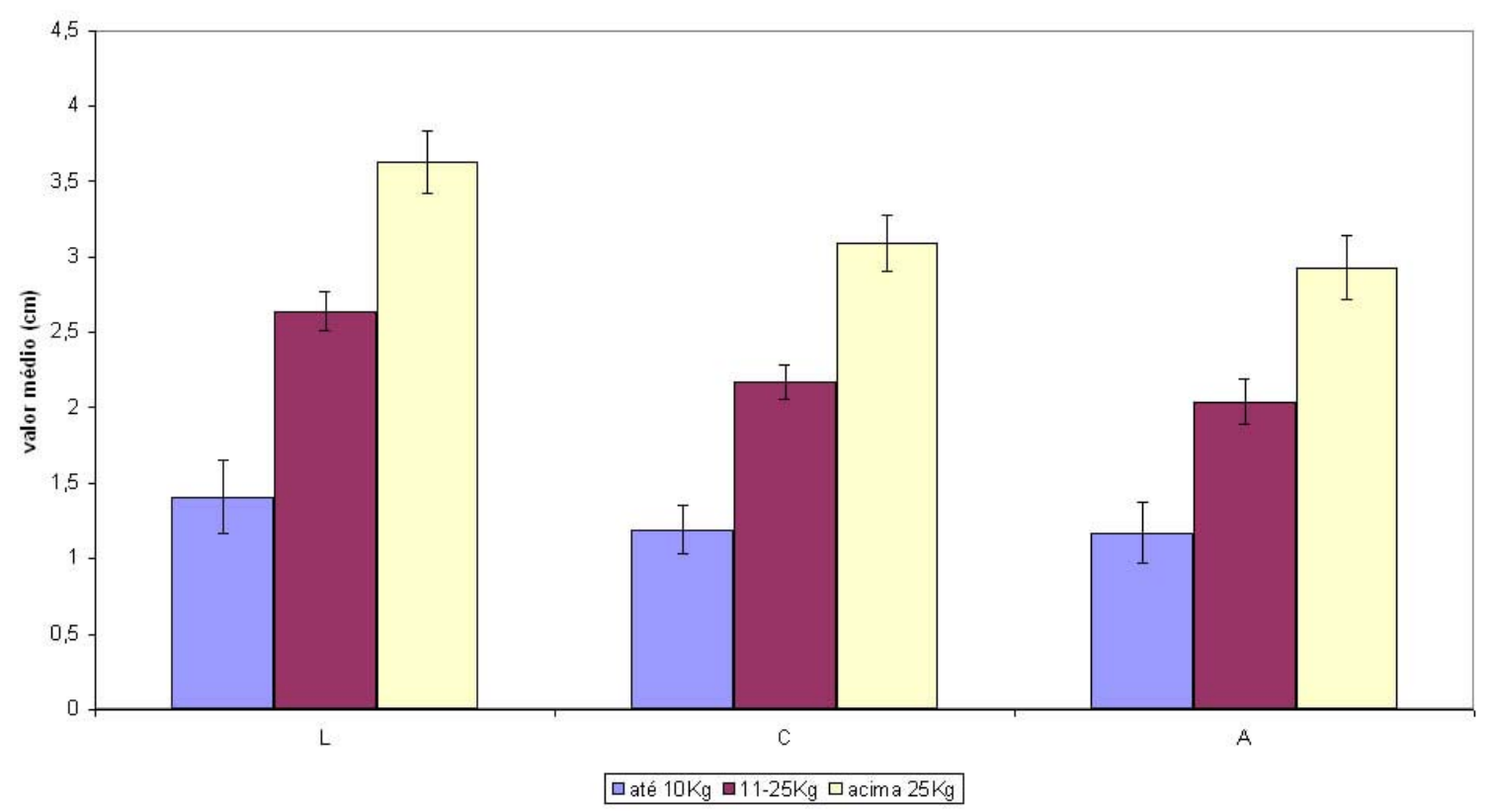

Gráfico 2 - Comparação entre diferentes faixas de peso corpóreo dos valores médios de largura (L), comprimento (C) e altura (A) da próstata dos cães do Grupo 1 (até 30 meses de idade), atendidos no Serviço de Diagnóstico por Imagem do HOVET/USP - São Paulo, Novembro de 2006

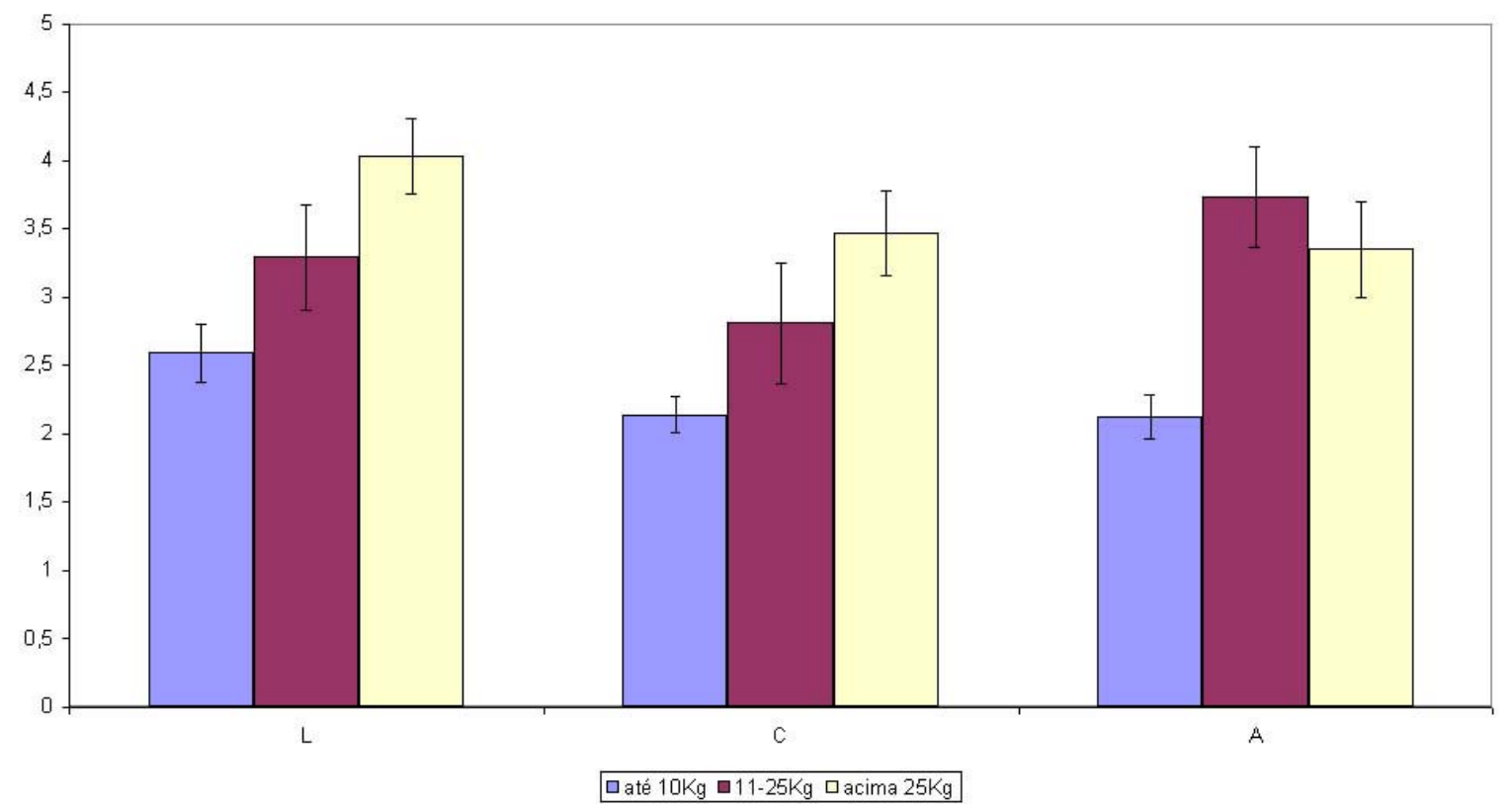

Gráfico 3 - Comparação entre diferentes faixas de peso corpóreo dos valores médios de largura (L), comprimento (C) e altura (A) da próstata dos cães do Grupo 2 (de 31 a 60 meses de idade), atendidos no Serviço de Diagnóstico por Imagem do HOVET/USP - São Paulo, Novembro de 2006 
No presente trabalho foi calculado o coeficiente de correlação linear de Pearson utilizando-se o programa Excel. O coeficiente de correlação é o grau de relação existente entre duas medidas. Este cálculo foi feito entre as medidas obtidas dentro de cada grupo, para que fosse calculado se há, ou não, uma tendência das medidas serem proporcionais. Os resultados obtidos foram os seguintes:

Grupo 1 - A correlação tanto entre o comprimento e a largura, quanto entre a largura e a altura e entre o comprimento e a altura foi de 0,99.

Grupo 2 - A correlação entre comprimento e largura foi de 0,96. A correlação entre largura e altura foi de 0,95 e a correlação entre comprimento e altura 0,95, também.

Tanto no Grupo 1 quanto no Grupo 2, as três medidas apresentaram uma correlação forte, o que significa que há uma forte tendência de uma medida aumentar conforme a outra aumentar.

Para cada correlação entre duas medidas foi feita uma regressão linear utilizando o teste ANOVA com nível de significância 5\%. A regressão linear serve para estimar medidas não coletadas.

Neste teste ANOVA, a partir do nível de significância escolhido 5\%, a decisão de aceitar a regressão pode ser realizada comparando o $\mathrm{F}$ de significação com o nível de significância. O F de significação é um valor obtido pelo teste ANOVA para ser comparado com o nível de significância quando se deseja verificar se o ajuste escolhido é significativo ou não. Para que a regressão linear seja significativa o valor do $\mathrm{F}$ de significação tem que ser menor que 5\% (nível de significância). 
Pelo teste ANOVA obteve-se um valor para o F de significação de cada correlação e observou-se que tanto no Grupo 1 quanto no Grupo 2 as correlações são significativas.

Os gráficos 4 a 9 mostram que a regressão linear foi significativa, pois os pontos iniciais estão próximos da reta ajustada.

A equação para o cálculo do valor não obtido é: $\mathbf{y}=a \cdot \mathbf{x}+b$, onde os coeficientes a e b são calculados pelo programa Excel, assim como o $R^{2}$ que indica a porcentagem de qualidade da reta em relação aos pontos iniciais. Os pontos de dispersão representam os valores encontrados na pesquisa.

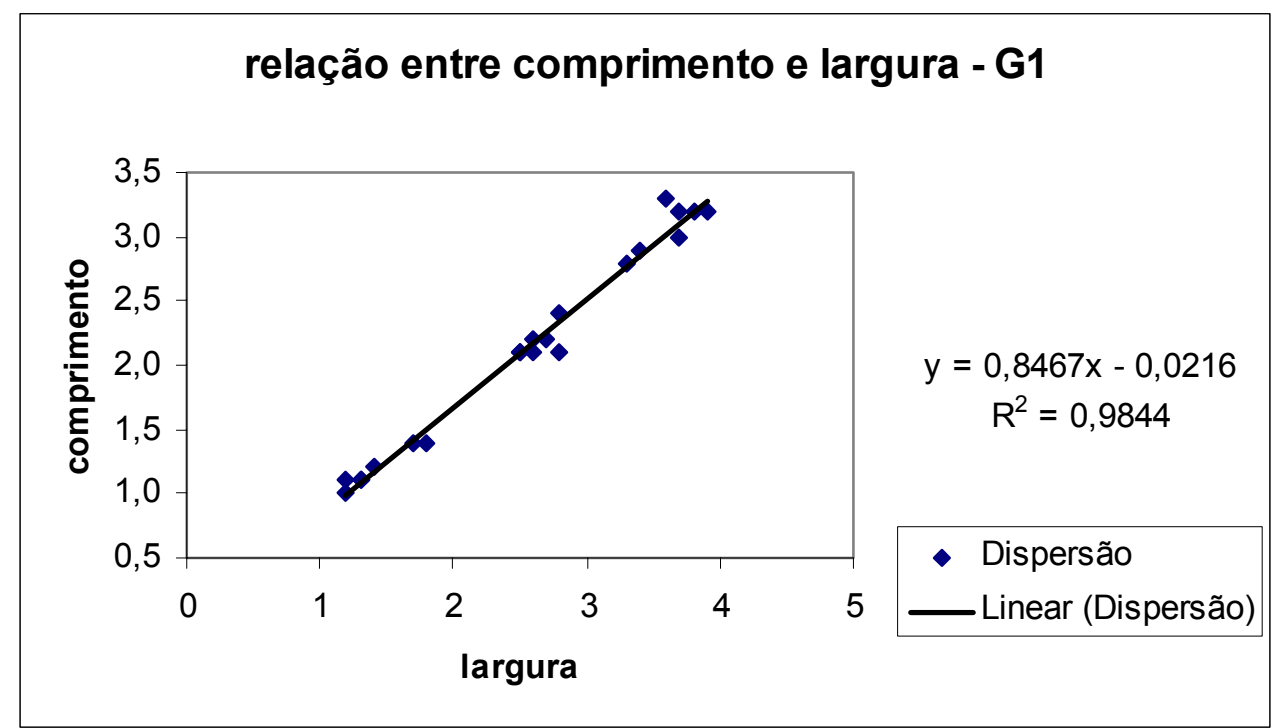

Gráfico 4 - Ajuste das medidas, comprimento e largura, obtidas pelo exame ultra-sonográfico da próstata dos cães examinados no Grupo 1 HOVET/USP - São Paulo, Novembro de 2006 


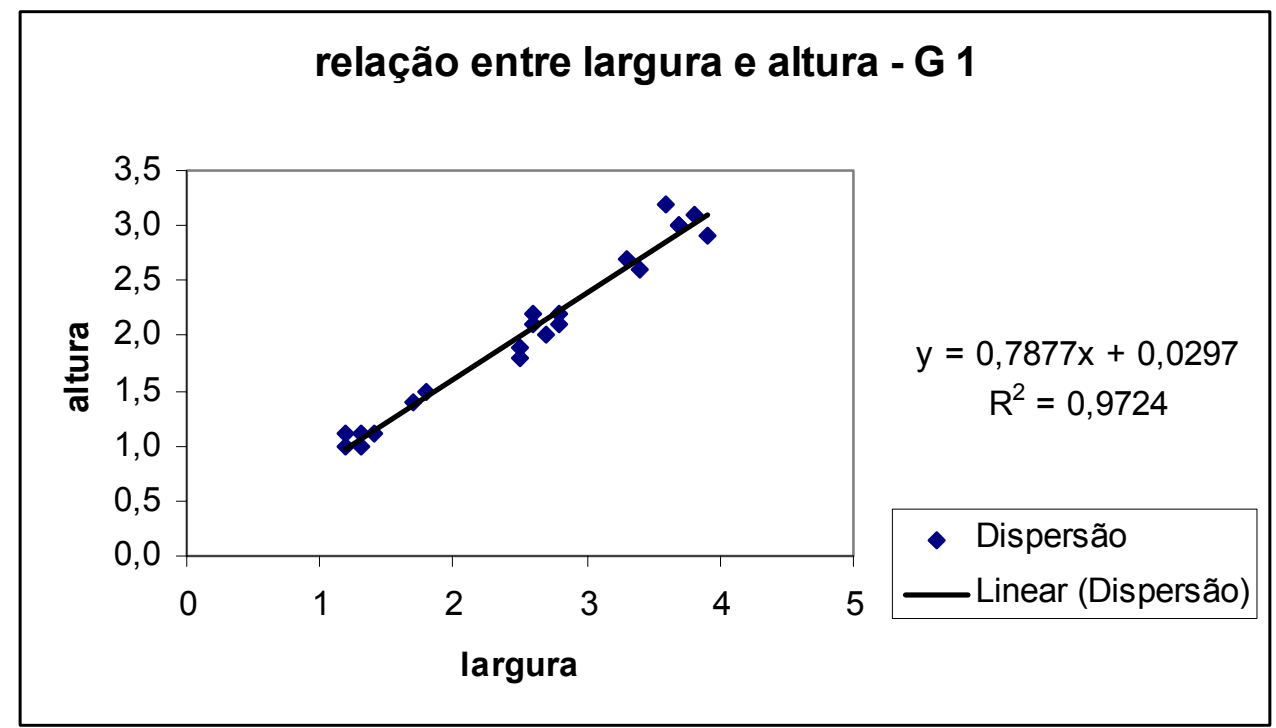

Gráfico 5 - Ajuste das medidas, largura e altura, obtidas pelo exame ultra-sonográfico da próstata dos cães examinados no Grupo 1 - HOVET/USP São Paulo, Novembro de 2006

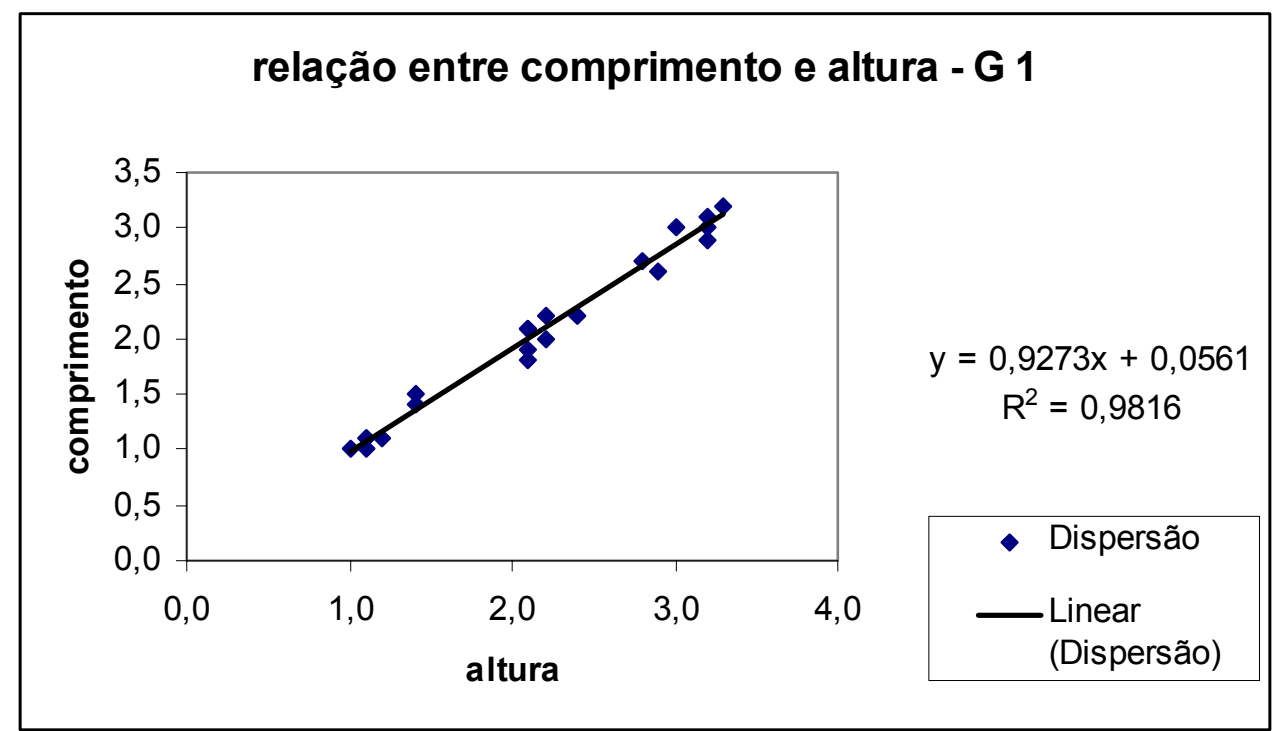

Gráfico 6 - Ajuste das medidas, comprimento e altura, obtidas pelo exame ultra-sonográfico da próstata dos cães examinados no Grupo 1 HOVET/USP São Paulo, Novembro de 2006 


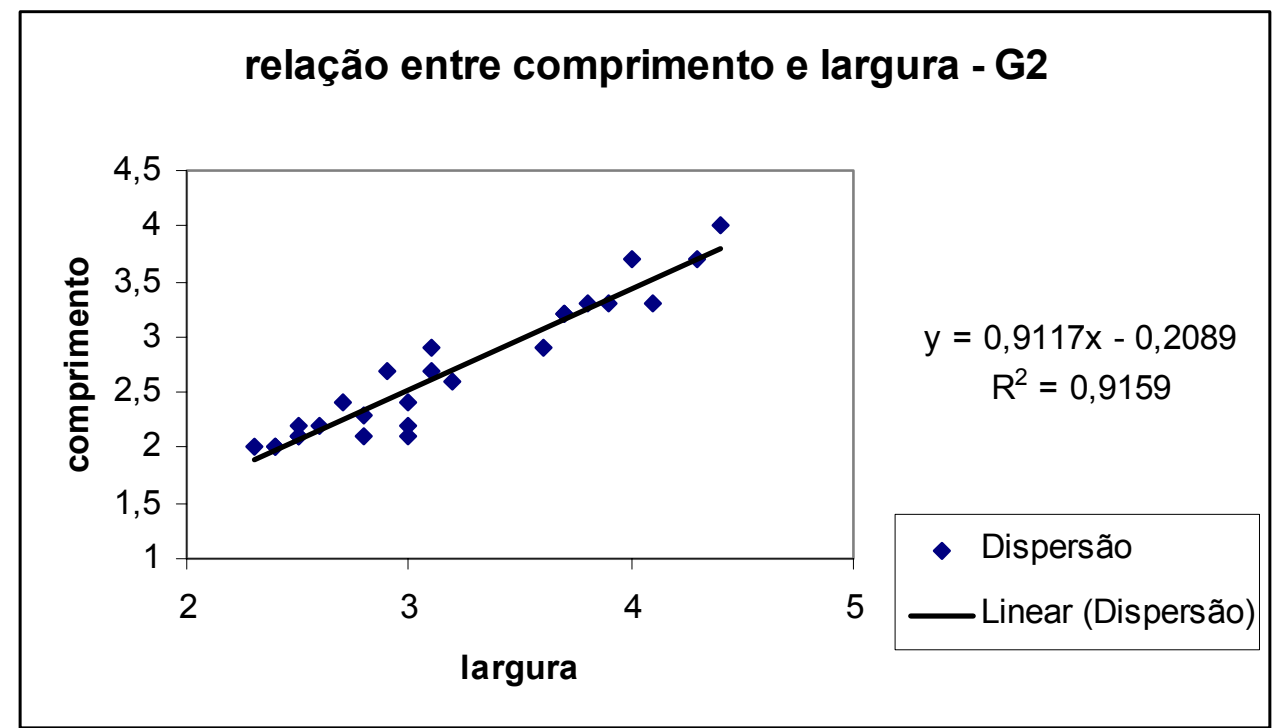

Gráfico 7 - Ajuste das medidas, comprimento e largura, obtidas pelo exame ultra-sonográfico da próstata dos cães examinados no Grupo 2 HOVET/USP - São Paulo, Novembro de 2006

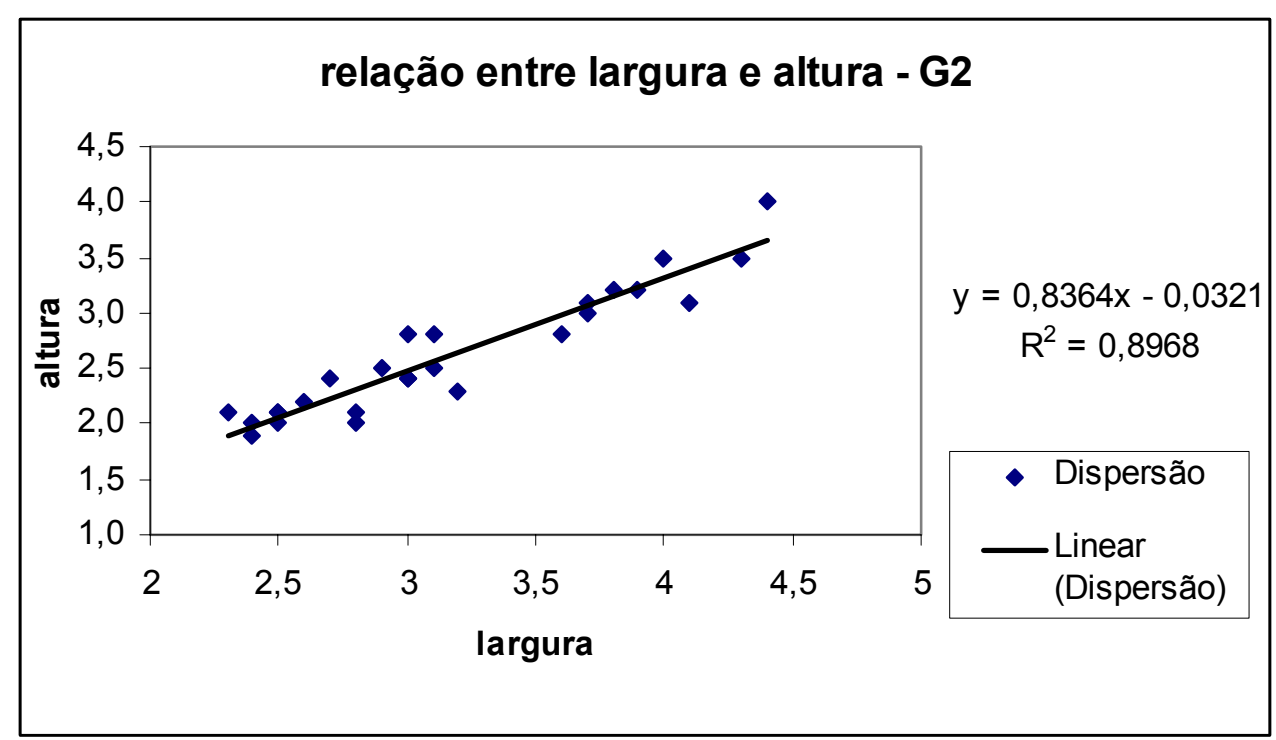

Gráfico 8 - Ajuste das medidas, largura e altura, obtidas pelo exame ultra-sonográfico da próstata dos cães examinados no Grupo 2 HOVET/USP - São Paulo, Novembro de 2006 


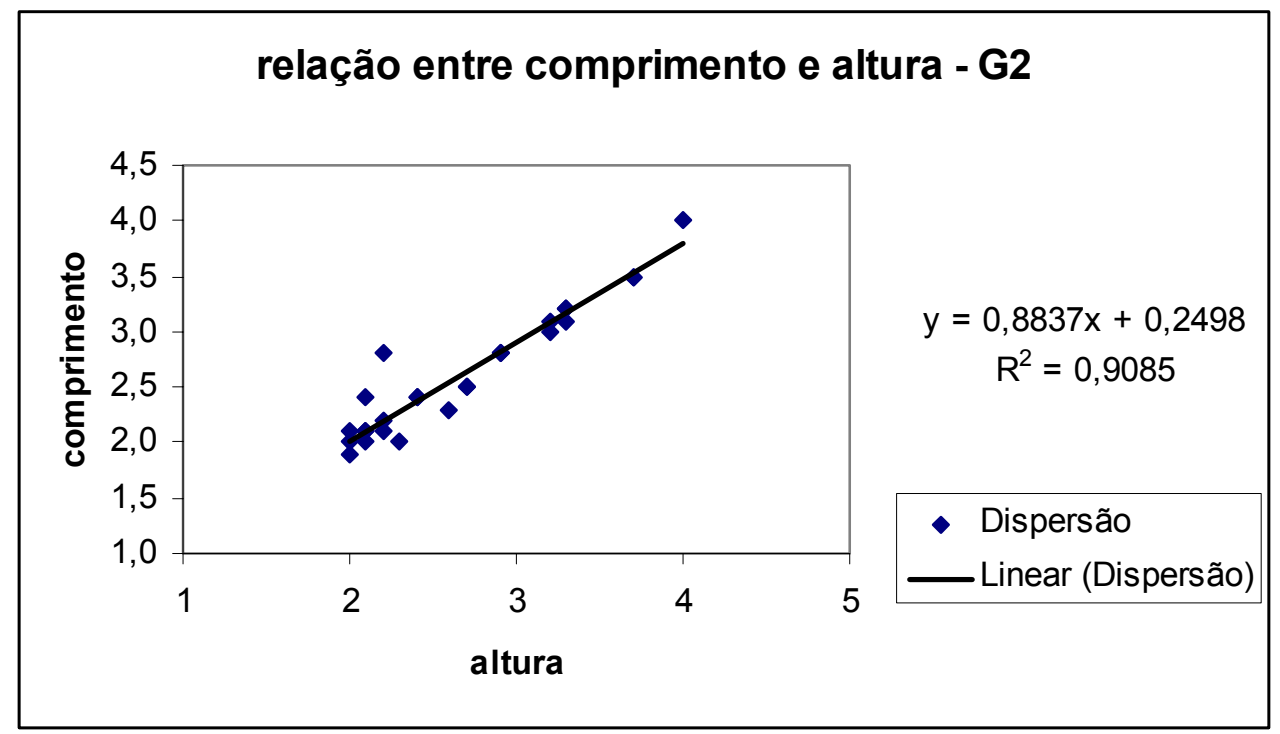

Gráfico 9 - Ajuste das medidas, comprimento e altura, obtidas pelo exame ultra-sonográfico da próstata dos cães examinados no Grupo 2 HOVET/USP São Paulo, Novembro de 2006 


\section{DISCUSSÃO}

Neste estudo, a escolha da mensuração da próstata pelo exame ultrasonográfico levou em conta o fato de ser uma técnica não invasiva, indolor e de menor custo para o proprietário, comparada com técnicas de imagem mais modernas como a tomografia computadorizada e a ressonância magnética (HERRIG, 1985).

O exame ultra-sonográfico da próstata do cão é uma técnica mais eficiente para a obtenção de medidas da estrutura prostática quando comparado ao das medidas obtidas radiograficamente (ATALAN; BARR; HOLT, 1999a; BLUM et al., 1985; CARTEE; ROWLES, 1983; COONEY; CARTEE; RUMPH, 1992; SCHAEFFTER, 2000).

O exame ultra-sonográfico fornece boa definição dos limites estruturais da próstata, e permite uma excelente avaliação do parênquima deste órgão (ATALAN et al., 1999a; CARTEE et al., 1990; COONEY; CARTEE; RUMPH, 1992; RUEL et al., 1998). Na próstata, a presença de lesões cavitárias, assim como lesões parenquimatosas, sejam elas de forma focal, multi-focal ou difusa, podem ser identificadas, avaliadas e mensuradas de forma eficaz pelo exame ultra-sonográfico (JOHNSTON et al., 1991; MURASHIMA, 2001; PETER et al., 1992). Estes fatores foram fundamentais na escolha da ultra-sonografia como técnica de imagem para mensurar a próstata do cão, pois, com este exame não só se obtiveram os valores necessários para a padronização das medidas da próstata como também se puderam descartar os cães que apresentaram algum tipo de alteração ultra-sonogáfica no parênquima prostático. 
Atalan, Barr e Holt, (1999a), Nyland e Matoon (1995), Murashima (2001) e Schaeffter (2000), ressaltam a importância de que a padronização das medidas prstáticas deve ser realizado em cães hígidos com idade até 60 meses. As enfermidades que acometem a próstata canina alteram o tamanho e a morfologia clássica da glândula (ELLENPORT, 1981; EVANS, 1993). Mais de $80 \%$ dos cães com idade superior a cinco anos, machos, não castrados possuem alterações histológicas compatíveis com HPB (SIRINARUMITR, 2001). Assim, para que fossem obtidos valores mais precisos das medidas prostáticas de cães com o menor risco de alterações no tamanho, causadas pela HPB, foi estipulado como idade máxima de cinco anos, para condução deste estudo.

A utilização do transdutor linear fica limitada, pois seu formato retangular torna difícil a realização do exame ultra-sonográfico nesta região caudal do abdômen, principalmente quando se avalia a próstata na imagem de corte transversal, devido à posição do pênis na espécie em estudo (CARTEE; ROWLES, 1983).

O protocolo para contenção e posicionamento do animal para a realização do exame ultra-sonográfico, não apresenta muitas variações. 0 posicionamento do animal em decúbito dorsal ou lateral e a utilização dos transdutores de 5,0 MHz e 7,5 MHz (ATALAN; BARR; HOLT, 1999a; ATALAN; BARR; HOLT, 1999b; CARTEE; ROWLES, 1983; GREEN; HOMCO, 1996; GUIDO, 2004; MURASHIMA, 2001; SCHAEFFTER, 2000) foram adequados e suficientes para a localização, mensuração e avaliação da próstata canina pelo exame ultra-sonográfico no presente estudo. Não foi necessário nenhum tipo de contenção química e o equipamento utilizado permitiu a identificação de 
alterações prostáticas nos casos dos animais que foram, então, excluídos. Em geral, no grupo de animais de até $10 \mathrm{~kg}$ foi utilizado o transdutor de $7,5 \mathrm{MHz}$ para se fazer as medidas e, nos demais, o de $5,0 \mathrm{MHz}$, mas vale ressaltar que a associação de ambos pode trazer informações complementares importantes.

$\mathrm{Na}$ tentativa de tornar a avaliação do tamanho da próstata menos subjetiva e frente à necessidade de mais estudos em relação às dimensões prostáticas em cães hígidos, sexualmente maduros e jovens, citada por Nyland e Matoon (2002), acredita-se ter colaborado para a determinação de valores de normalidade de tamanho prostático canino. A grande variedade de raças caninas existentes dificulta o estudo por raça e, por isso, se optou pela divisão por faixas de peso corpóreo.

Para a realização das mensurações ultra-sonográficas da próstata nos animais da espécie canina, este projeto se baseou nas metodologias preconizadas por Atalan, Barr e Holt (1999a), Atalan, Barr e Holt (1999b), Blum et al. (1985), Cartee e Rowles (1983), Guido (2004), Murashima (2001), Ruel et al. (1998), Santos et al. (2004) e Schaeffter (2000), onde o comprimento foi considerado como a distância máxima entre as margens cranial e caudal em imagem realizada em corte longitudinal, a largura como a distância máxima entre as margens laterais em imagem realizada em corte transversal e a altura como sendo o maior diâmetro perpendicular ao eixo do comprimento.

Alguns trabalhos, para mensuração da próstata canina, realizados nestes últimos dez anos, foram concluídos de forma ampla e genérica, sem estabelecimento de correlações entre valores métricos e variáveis como peso e idade (RUEL et al., 1998). 
Neste experimento, os pacientes foram divididos de acordo com o peso e a idade como apresentado no Quadro 1.

Utilizando animais com idade abaixo de cinco anos e com peso entre 11 e 30 kg, Kalmopatana et al. (2000) obtiveram as seguintes medidas prostáticas: comprimento $3,15 \mathrm{~cm}$, largura $3,15 \mathrm{~cm}$ e altura $2,83 \mathrm{~cm}$. Estas medidas são semelhantes aos valores obtidos no Subgrupo 3. Ruel et al. (1998) também obtiveram medidas semelhantes: comprimento $3,4 \mathrm{~cm}$, largura $3,3 \mathrm{~cm}$ e altura $2,8 \mathrm{~cm}$, porém os autores comentam a possibilidade da existência de hiperplasia prostática benigna nos animais por eles estudados, pois incluíram, neste trabalho, cães de até 14 anos.

Santos et al. (2004), realizaram estudo com 47 cães da raça Dogue Alemão para mensurar a próstata pelo exame ultra-sonográfico, in vivo. A idade mínima dos pacientes foi de 1,5 anos e a máxima de 6 anos. Os valores obtidos foram de: comprimento $4,04 \mathrm{~cm}$ e largura $4,00 \mathrm{~cm}$. O peso e a idade dos animais estudados por Santos et al. (2004) são semelhantes aos pacientes estudados por Schaeffter (2000), que padronizou, pelo exame ultrasonográfico, as medidas da próstata de cães da raça Pastor Alemão com idade entre 1 e 7 anos e obteve os valores: comprimento $3,59 \mathrm{~cm}$, largura $3,45 \mathrm{~cm}$ e altura $4,63 \mathrm{~cm}$. Estes dois trabalhos tiveram seus resultados comparados com os valores obtidos neste estudo no Subgrupo 6 e observou-se que, conforme o esperado, as medidas foram semelhantes.

Murashima (2001) apresenta maior possibilidade de comparação com este trabalho, pois, em seu experimento, o autor utilizou um número significativo de cães de diferentes raças e tamanhos com idades entre 1 e 4 
anos, sendo que, os valores obtidos nas medidas ultra-sonográficas das próstatas também foram confrontadas com idade e peso dos animais.

Murashima (2001) dividiu os 45 cães estudados em três grupos de acordo com a massa corporal. O Grupo 1 foi composto por 12 cães pesando entre 2,0 e 6,0 kg, tendo como medidas: comprimento 2,01 cm, largura 2,38 cm e de altura 2,05 cm, valores semelhantes aos por nós obtidos no Subgrupo 4. O Grupo 2, composto por 23 cães com massa corpórea variando entre 7,0 e 15 kg apresentou os valores: comprimento 2,35 cm, largura 2,51 cm e altura 2,06 $\mathrm{cm}$, valores semelhantes aos obtidos no Subgrupo 2. O Grupo 3, foi composto por 10 cães pesando entre 22 e 57 kg, tendo como medidas: comprimento 3,18 $\mathrm{cm}$, de largura $3,45 \mathrm{~cm}$ e de altura $3,06 \mathrm{~cm}$, valores semelhantes aos obtidos no Subgrupo 3.

Apesar da análise de regressão linear permitir o estabelecimento de equações matemáticas para o cálculo de medidas da altura, comprimento ou largura, baseado no valor de apenas uma dessas três medidas, na maioria das vezes, o bom comportamento do animal durante o exame ultra-sonográfico permite a realização das três medidas diretamente pela imagem ultrasonográfica, não necessitando o uso da equação matemática. De qualquer forma, neste estudo, o forte índice de correlação permite dizer que há uma tendência a aumentar, proporcionalmente, largura em relação ao comprimento, altura em relação à largura, comprimento em relação à altura e vice-versa.

O crescente estudo da padronização do tamanho normal da próstata canina, em animais hígidos, será sempre, um grande auxílio na investigação e diagnóstico das prostatopatias. 
Em geral, os valores das medidas da próstata de cães normais de trabalhos realizados com raças pré-determinadas, se aproximaram dos valores deste presente estudo, quando comparados aos subgrupos de faixas de peso corpóreo a que pertenciam. Esse fato reforça a importância do exame ultrasonográfico como técnica auxiliar para diagnóstico de prostatomegalias e, pelo pequeno desvio padrão obtido, pode-se sugerir a utilização de padronização de medidas da próstata normal de cães por faixa de peso, o que facilitaria bastante, visto a grande variedade de raças canina existente.

O fato de ter sido encontrada uma diferença estatisticamente significante dos valores médios das medidas da próstata entre o Grupo 1 (até 30 meses) e o Grupo 2 (de 31 a 60 meses), justifica a utilização de valores de referência para tamanho normal da próstata do cão por faixa etária.

Tendo como base as informações obtidas em literatura e os resultados obtidos neste trabalho, acredita-se que o exame ultra-sonográfico deva continuar sendo utilizado nos estudos da próstata canina para que seja possível, cada vez mais, obter informações complementares sobre as alterações do tamanho da próstata em cães, auxiliando no estabelecimento do diagnóstico, bem como na evolução do tratamento de prostatopatias desta espécie. 
CONCLUSÕES 


\section{CONCLUSÕES}

A análise dos resultados obtidos neste trabalho permitiu concluir que:

1. pode-se observar um discreto aumento de tamanho da glândula prostática dos cães com idade entre 31 e 60 meses quando comparados aos animais de idade até 30 meses, o que deve ser considerado quando o mesmo for avaliado pela técnica de ultra-sonografia;

2. Pode-se observar que há uma tendência a aumentar o tamanho da próstata conforme o aumento de massa corpórea do cão, sendo que, estatisticamente, esta tendência não é significativa;

3. Existe forte correlação entre comprimento, largura e altura da próstata do cão normal, podendo-se estabelecer equações matemáticas que permitam, por meio de um desses três valores de medida, obter os outros dois. 
REFERÊNCIAS 


\section{REFERÊNCIAS}

ACKERMAN, N. Radiology and ultrasound of urogenital diseases in dogs and cats. lowa: lowa State University Press, 1991. 187 p.

ATALAN, G.; BARR, F. J.; HOLT, P. E. Comparasion of ultrasonographic and radiographic measurements of canine prostate dimensions. Veterinary Radiology and Ultrasound, v. 40, n. 4, p. 408-412, 1999a.

ATALAN, G.; HOLT, P. E.; BARR, F. J. Ultrasonographic estimation of prostate size in normal dogs and relationship to bodyweight and age. Journal of Small Animal Practice, v. 40, n. 3, p. 119-122, 1999b.

ATALAN, G.; HOLT, P. E.; BARR, F. J.; BROWN, P. J. Ultrasonographic estimation of prostatic size in canine cadavers. Research in Veterinary Science, v. 67, n. 1, p. 7-15, 1999c.

BARR, F.J. Diagnostic ultrasound in the dog and cat. Oxford: Blackwell Scientific, 1990, p. 65-77.

BARSANTI, J. A.; FINCO, D. R. Moléstias prostáticas do cão. In: ETTINGER, S. J. Tratado de medicina interna veterinária. 3. ed. São Paulo: W. B. Saunders, 1992. v. 4, p. 1941-1963.

BASINGER, R. R.; ROBINETTE, C. L.; HARDIE, E. M.; SPAULDING, K. A. The prostate. In: SLATTER, D. Textbook of small animal surgery. $2^{\text {nd }}$ ed. Philadelphia: W.B. Saunders, 1993. v. 2, p. 1349-1367.

BLUM, M. D.; BAHNSON, R. R.; LEE, C.; DESCHLER, T. W.; GRAYHACK, J. $\mathrm{T}$. Estimation of canine prostatic size by in vivo ultrasound and volumetric measurement. Journal Urology, v. 133, p. 1082-1086, 1985. 
BOLAND, L. E.; HARDIE, R. J.; GREGORY, S. P.; LAMB, C. R. Ultrasoundguided percutaneous drainage as the primary treatment for prostatic abscesses and cysts in dogs. Journal of the American Animal Hospital Association, v. 39, n. 2, p. 151-159, 2003.

BOMASSI, E.; TESTAULT, I.; ROUSSELOT, J. F. Echos D'Echo: Fiche n. 1. Pratique Médicale et Chirurgicale de L’Animal de Compagne, v. 35, n. 5, p. 381-383, 2002.

CARTEE, R. E.; ROWLES, T. Transabdominal sonographic evaluation of the canine prostate. Veterinary Radiology, v. 24, n. 4, p. 156-164, 1983.

CARTEE, R. E.; RUMPH, P. F.; KENTER, D. C.; COONEY, J. C.; FRANK D. Evaluation of drug-induced prostatic involution in dogs by transabdominal Bmode ultrasonography. American Journal of Veterinary Research, v. 51, n. 11, p. 1773-1778, 1990.

CARTEE, R. E. Practical Veterinary Ultrasound. Philadelphia: Williams \& Wilkins, 1995, $329 \mathrm{p}$.

COONEY, J. C.; CARTEE, B. W.; RUMPH, P. F. Ultrasonography of the canine prostate with histologic correlation. Theriogenology, v. 38, p. 877-895, 1992.

CRISTENSEN, G. C. The urogenital system and mammary glands. In: MILLER, E. M.; CRISTENSEN, G. C.; EVANS, H. E. Anatomy of the dog. Philadelphia: W. B. Saunders, 1964. p. 762-763.

DUGRAGNE, C.; BEGON, D. Imagerie du bas appareil urinaire et de la prostate. Recueil de Medicine Veterinaire, v. 172, n. 1, p. 117-128, 996.

ELLENPORT, C. R. Aparelho urogenital. In: GETTY, R. SISSON / GROSSMAN anatomia dos animais domésticos. 5. ed. Rio de Janeiro: Interamericana, 1981. p. 1485-1488. 
EVANS, H. E. Miller's anatomy of the dog. 3.ed. Philadelphia: W. B. Saunders, 1993. $1113 p$.

FEENEY, D. A.; JOHNSTON, G. R.; KLAUSNER, J. S. Two-dimensonal, grayscale ultrasonography. Applications in canine prostatic disease. The Veterinary Clinics of North America: Small Animal Practice, v. 15, n. 6, p. 1159-1176, 1985.

FEENEY, D. A.; JOHNSTON, G. R.; KLAUSNER, J. S.; PERMAN, V.; LENINGER, J. R.; TOMLINSON, M. J. Canine prostatic disease - comparision of radiographic appearance with morphologic and microbiologic findings: 30 cases (1981-1985). Journal of the American Veterinarian Medical Association, v. 190, n. 8, p. 1018-1026, 1987a.

FEENEY, D. A.; JOHNSTON, G. R.; KLAUSNER, J. S.; PERMAN, V.; LENINGER, J. R.; TOMLINSON, M. J. Canine prostatic disease - comparision of ultrasonographic appearance with morphologic and microbiologic findings; 30 cases (1981-1985). Journal of the American Veterinarian Medical Association, v. 190, n. 8, p. 1027-1034, 1987b.

FEENEY, D. A.; JOHNSTON, G. R.; WALTER, P. A. Ultrasonography of the kidney and prostate gland. Problems in Veterinary Medicine, v. 3, n. 4, p. 619-646, 1991.

GREEN, R. W.; HOMCO, L. D. Prostate gland. In: GREEN, R. W. (Ed.). Small Animal Ultrasound, Philadelphia: Lippincot-Raven, 1996. p. 237-250.

GUIDO, M. C. Ultra-sonografia do aparelho reprodutor masculine. In:

CARVALHO, C. F. Ultra-sonografia em pequenos animais. São Paulo: Roca, 2004. p. 213-223.

HERRING, D. S. Diagnostic ultrasound. The Veterinary Clinics of North America: Small Animal Practice, v. 15, n. 6, p. 1105, 1985. 
HOLM, H. H.; NORTHVED, A. A transurethral ultrasonic scanner. Journal of Urology, v. 111, p. 238-241, 1974.

KALMOPATANA, K.; JOHNSTON, G. R.; JOHNSTON, S. D. Determination of canine prostatic volume using transabdominal ultrasonography. Veterinary Radiology and Ultrasound, v. 41, n. 1, p. 73-77, 2000.

KRAWIEC, D. R. Canine prostate disease. Journal of America Veterinary Medical Association, v. 204, n. 10, p. 1561-1564, 1994.

JOHNSTON, G. R.; FEENEY, D. A.; RIVERS, B.; WALTER, P. A. Diagnostic imaging of the male canine reproductive organs. The Veterinary Clinics of North America: Small Animal Practice, v. 21, n. 3, p. 553-589, 1991.

LATTIMER, J. C. The Prostate. In: THRALL, D. E. Textbook of Veterinary Radiology. Philadelphia: W. B. Saunders, 1986. p. 444-457.

LOWSETH, L. A.; GERLACH, R. F.; GILLET, N. A.; MUGGENBURG, B. A. agerelated changes in the Beagle dog. Veterinary Pathology, n. 27, p. 34-53, 1990.

MAÏ, W. Ultrasonography of the prostate in dogs and cats. Point Veterinaire, v. 33, n. 224, p. 70-74, 2002.

MARTINS, M. A. D. B. Acurácia da ultra-sonografia transabdominal para determinação de volume e massa prostáticos na espécie canina. 2003. 106 f. Dissertação (Mestrado em Medicina Veterinária) - Faculdade de Medicina Veterinária e Zootecnia, Universidade de São Paulo, São Paulo, 2003.

MURASHIMA, J. C. Mensuração da próstata por ultra-sonografia transabdominal, e sua associação com a massa corpórea de cães adultos e clinicamente sadios. 2001. 51f. Dissertação (Mestrado em Medicina 
Veteriária) - Faculdade de Medicina Veterinária e Zootecnia, Universidade Estadual Paulista, Botucatu, 2001.

MUZZI, L. A.; MUZZI, R. A. L.; ARAÚJO, R. B. Ultra-sonografia da próstata em cães. Clínica Veterinária, v. 2, n. 11, p. 19-22, 1997.

NEWELL, S. M.; NEUWIRTH, L.; GINN, P. E.; ROBERTS, G. D.; PRIME, L. S.; HARRISON,L. M. Doppler ultrasound of the prostate in normal dogs and dogs with chronic lymphocytic-lymphoplasmocytic prostatitis. Veterinary Radiology and Ultrasound, v. 39, n. 4, p. 332-336, 1998.

NYLAND, T. G.; MATTOON, J. S. Small Animal Diagnostic Ulttrasound. 2nd. ed. Philadelphia, W.B: Saunders, 2002, 461p.

O'SHEA, J. D. Studies on the canine prostate gland. The Journal of Comparative Pathology and Therapeutics, v. 72, n. 3, p. 321-331, 1962.

PENNICK, D. G. Ultrasonography. The Veterinary Clincs of North America: Small Animal Practice, v. 28, n. 4, p. 755-75, 1998.

PETER, A. T.; JAKOVLJEVIC, S. Real-Time ultrasonography of the small animal reproductive organs. Compendium on Continuous Education for Practicing Veterinarian, v. 14, n. 6, p. 739-746, 1992.

ROOT, C. R.; SPAULDING, K. A. Diagnostic imaging in companion animal theriogenology. Seminary of Veterinary Medicine Surgery Small Animal, v. 9, p. 7-27, 1994.

RUEL, Y.; BARTHEZ, P. Y.; MAILLES, A.; BEGON, D. Ultrasonographic evaluation of the prostate in healthy intact dogs. Veterinary Radiology and Ultrasound, v. 39, n. 3, p. 212-216, 1998. 
SANTOS, S. E. C.; GARCIA, J. F.; VANNUCCHI, C. I.; MALDONADO, A. L. L.; SANTOS, F. A. M. Medidas ultra-sonográficas do aparelho reprodutor de cães da raça Dogue Alemão. Revista Portuguesa de Ciências Veterinárias, v. 99, n. 550, p. 123-124. 2004.

SCHAEFFTER, C. O. D. Aspectos ultra-sonográficos da próstata de cães da raça Pastor Alemão. 2000. 96 f. Tese (Doutorado em Medicina Veterinária) - Faculdade de Medicina Veterinária e Zootecnia, Universidade de São Paulo, São Paulo. 2000.

SELCER, B. A. The reproductive system: the prostate. In: CARTEE, R. E. Practical Veterinary Ultrasound. Philadelphia: Williams \& Wilkins, 1995. p. 252-258.

SIRINARUMITR, K.; JOHNSTON, S. D.; ROOT, K. M. V.; JOHNSTON, G. H.; SARKAR, D. K.; MEMON, M. A. Effects of finasteride on size of the prostate gland and semen quality in dogs with benign prostatic. Journal of the American Veterinary Medical Association, v. 218, n. 8, p. 1275-1278, 2001.

ZEKAS, L. J.; FORREST, L. J.; SWAINSON, S.; PHILLIPS, L. A. Radiographic diagnosis: mineralized paraprostatic cyst in a dog. Veterinary Radiology and Ultrasound, v. 45, n. 4, p. 310-311, 2004.

ZOHIL, A. M.; CASTELLANO, M. C. Prepubic and transretal ultrasonography of the canine prostate: a comparative study. Veterinary Radiology and Ultrasound, v. 36, n. 5, p. 393-396, 1995. 
APÊNDICE 


\section{APÊNDICE}

Protocolo utilizado para identificação dos pacientes, histórico clínico e anotações referentes ao exame ultra-sonográfico da próstata

- Identificação do animal

nome:

raça:

idade:

peso:

número de cadastro:

proprietário:

endereço:

- Histórico de doenças do trato genito-urinário:

- Histórico de doenças sistêmicas:

- Hemograma:

- Urinálise:

- Descrição do exame ultra-sonográfico da próstata

ecotextura:

contornos:

ecogenicidade:

medida crânio-caudal:

medida dorso-ventral:

medida latero-lateral: 